\title{
RISK ASSESSMENT DUE TO TERRORIST ACTIONS ON PUBLIC TRANSPORTATION NETWORK: A CASE STUDY IN PORTUGAL
}

\author{
João M. Pereira ${ }^{\text {**, Paulo B. Lourenço }}{ }^{\text {a }}$ \\ ${ }^{a}$ ISISE, Department of Civil Engineering, University of Minho, Guimarães, Portugal \\ * Corresponding author: Department of Civil Engineering, University of Minho, \\ Campus de Azurém, Guimarães, 4800-058, Portugal; email: jpereira@civil.uminho.pt
}

\begin{abstract}
The work presented in this paper was performed in collaboration with one of the largest Public Transportation Operator in Portugal and addresses the problem of risk assessment due to terrorist actions involving explosions at different levels. First, a region of the Operator is selected. The elements in the Operator's network with the highest associated risk are highlighted for each threat using the COUNTERACT guidelines. Subsequently, from the group of elements with the highest associated risk, an element is selected for structural safety evaluation under blast loading. Through numerical analysis, different explosion scenarios are studied and the behavior of the structure is presented.
\end{abstract}

Keywords: Public Transportation Infrastructure; Risk assessment; COUNTERACT; Blast loading; Structural safety 


\section{Introduction}

Terrorism has been described as the deliberate use of violence to create a sense of shock, fear and outrage in the mind of the target population [1]-[3]. Armed attacks and bombings constituted nearly $80 \%$ of all terrorist attacks in 2011. Suicide attacks accounted for just $2.7 \%$ of terrorist attacks in 2011 but $21 \%$ of all terrorism-related fatalities, a fact that underscores their extreme lethality. IEDs (Improved Explosive Devices) were the most frequently used and deadliest terrorist weapon employed [4]. In the year of 2011, over two-thirds of all terrorist attacks struck infrastructure or facilities. Of those, transportation assets and public places were the most frequently targeted. Transportation facilities - such as vehicles, buses and transportation infrastructure incurred damage in about $39 \%$ of the attacks, while public places - including communal areas, markets, polling stations, religious institutions, schools and residences - incurred damage in about $28 \%$ of the attacks [4].

One of the reasons that make this easy to achieve is that developed societies have become very dependent on complex and fragile systems (railways, airlines, gas pipelines, electricity infrastructure, large shopping areas and business centers, etc.) which are both vulnerable and critical to society's functions, and provide the terrorists with many suitable targets. Attackers can use various weapon systems in different combinations and such events cannot be predicted. However, reliable information and objective threat and risk assessment can produce effective estimates of such incidents.

Risk Assessment must be understood as a step or a process inside the Risk Management model. Figure 1 shows a simplified representation of the Risk Management model. Risk Management is a systematic and analytical process by which an organization identifies, reduces, and controls its potential risks and losses [5]. This process allows organizations to determine the magnitude and effect of the potential loss, the likelihood of such loss actually happening, and the countermeasures that could lower the probability or magnitude of loss.

The first step is to conduct a threat assessment where the threat or hazard is identified, defined and quantified. The next step of this model is to identify the values of the asset that need to be protected. Once the asset values are known, the next step is to conduct a vulnerability assessment with an evaluation of the potential vulnerability of the critical assets against the identified threats or hazards. The next step is the risk assessment: by 
analyzing the threat, asset value, and vulnerability it is possible to ascertain the level of risk for each critical asset against applicable threats. The final step of this model is to consider mitigation options. Risk assessment on its own incorporates the first four steps described.

There are a number of methods available to conduct an organization's risk assessment, and the steps can be accomplished in different sequences. Examples are given in:

- FEMA 452, from the Federal Emergency Management Agency, USA, How-To Guide to Mitigate Potential Terrorist Attacks Against Buildings - considers a comprehensive methodology to prepare a risk assessment, providing means to assess the risk to the assets and to make risk-based decisions on how to mitigate those risks. The primary use of this methodology is for buildings, although it could be adapted for other types of critical infrastructure [6].

- ISO 31000, International Standards Organization, International Standard: Risk Management - provides organizations with guiding principles, a generic framework, and process for managing risk. It gives emphasis to considering risk in terms of the effect of uncertainty on objectives, rather than the risk incident [7].

- DEMA (The RVA model), from the Danish Emergency Management Agency, Approach to Risk and Vulnerability Analysis for Civil Contingency Planning has developed a generic scenario-based model for risk and vulnerability analysis. The model is developed for government agencies with responsibilities for society's critical functions [8].

- UFC 4-020-01, from the Department of Defence, USA, DoD Security Engineering Facilities Planning Manual - it includes a procedure for risk analysis as a part of a preliminary design criterion [9].

All the previous methodologies have one common objective: to apply a quantitative assessment process that identifies the assets at highest risk. One key factor that can lead to an effective risk assessment is the selection of the entities/people brought into the process. This assessment should have inputs from, but not limited to, police agencies, intelligence agencies, structural engineers and national emergency management agencies. 
Modern society is heavily dependent on transportation networks. In the past 60 years, these networks have been an appropriate target for terrorists [10]. They allow easy access and provide suitable cover for escape. They also provide concentrations of civilians and their slaughter never fails to generate high levels of public interest, both national and international. The attacks on the Spanish railway network in Madrid in March 2004, the Metro and Bus strikes in London in July 2005, the Mumbai train attacks in July 2006 and the bombing in the international arrival hall of Moscow's busiest airport in January 2011, among many others, all point to public passenger transport networks as being suitable terrorist targets.

COUNTERACT (Cluster Of User Networks in Transport and Energy Relating to antiterrorist ACTivities) was an European research project set up to improve security against terrorist attacks aimed at public passenger transport, intermodal freight transport and energy production and transmission infrastructure [11]. The project focused on the protection of critical transport infrastructures, public transport passengers and goods. It reviewed the existing security policies, procedures, methodologies and technologies to identify the best practices, which in turn have been promoted throughout the relevant security community in the EU. One of the main objectives of the project was to develop generic guidelines for conducting risk assessment in public transport networks.

This paper presents a risk assessment performed on a large Public Transport Operator in Portugal that allowed identifying the elements with the highest risk regarding each analyzed threat. From the elements with the highest risk, one was selected for a structural safety assessment regarding possible explosion scenarios.

\section{Risk assessment}

As stated previously, transportation infrastructure is the most targeted type of infrastructure when it comes to terrorist attacks. A risk assessment was performed on one of the largest Public Transportation Operator in Portugal. For confidentiality reasons, the Operator will be kept anonymous as it is not essential for the presented analysis. Performing a risk assessment analysis allows identifying the elements in the network with the highest risk regarding a specific threat and provides the decision makers with essential tools to prioritize possible interventions. The COUNTERACT 
methodology was chosen for its specific character regarding Public Transportation Operators. Next, the procedure and the obtained results will be presented.

\subsection{Identify key infrastructure}

In order to identify possible targets for attacks it is necessary to structure the whole PT (Public Transport) system in an operational diagram. To structure the system it is important to address, namely, the following aspects [11]:

a) How attractive is the city/region for terrorists compared to others?

b) How attractive is the PT system for terrorists compared to other potential targets in the city/region?

c) Which system elements are most attractive for terrorists?

d) Which parts of the network are most critical to the operation?

e) What is the number of passengers in interchange/stations/stops, vehicles (at peak times)?

f) Is there special/ large events organized nearby that could temporarily raise the risk level?

g) Are there institutions/ organizations nearby that generate a group of passengers which is at special risk?

A total of 73 elements were located in the selected part of the Operator's network. The types of elements located in the area under study were stations, administrative offices and operational centers. In order to focus the study on the elements with the highest relevance for the whole network, five criteria were considered on all elements. The selection of the criteria took into account the internal methodology for characterization of elements used by the Operator, being: a) $\mathrm{C} 1$ - passenger flow; b) $\mathrm{C} 2$ - service provided; c) C3 - mobility; d) C4 - significance; e) C5 - location, as indicated below. Different values for the sub-criteria and weights should be used for different Operators and conditions.

\subsubsection{C1-Passenger flow:}

The number of passenger starting or ending a journey at an element is an important indicator. This influences the design and maintenance of the element, and regarding this 
specific study, provides a direct relation with the potential victims of a possible attack. For each station a value of $\mathrm{C} 1$ is assigned based on the following equations:

$$
\begin{array}{rlrl}
V_{i}<10000 & C 1_{i} & =\left(\frac{V_{i}-V_{\text {min }}}{10000-V_{\text {min }}}\right) \times 25 \\
C 1_{i}= & C 1_{i} & =\left(\frac{V_{i}-10000}{50000-10000}\right) \times 25+25 \\
10000 \leq V_{i}<50000 & & & \\
50000 \leq V_{i}<250000 & =\left(\frac{V_{i}-50000}{250000-50000}\right) \times 25+50 \\
V_{i} & \geq 250000 & C 1_{i} & =\left(\frac{V_{i}-250000}{V_{\text {max }}-250000}\right) \times 25+75
\end{array}
$$

Where $C 1 i$ is the value of criteria $\mathrm{C} 1$ for element $i$; $i$ is the monthly passenger flow for element $i$; Vmin is the minimum monthly passenger flow for all elements under analysis; and Vmax is the maximum monthly passenger flow for all elements under analysis.

\subsubsection{C2 - Service provided:}

The service provided at a specific element affects the distance covered during the journey, the amount of time a passenger stays in the element, and the frequency of transport, among other aspects. The service reflects the tributary area associated with the element. The services considered should be those provided by the Operator. As an example, for Operators regarding train transportation, the services could be: Suburban, Regional, Inter-Regional, Inter-City, and International; or any other provided by the Operator. For each element, a value of $\mathrm{C} 2$ is assigned based on the following equation:

$C 2_{i}=\sum S_{p i}$

Where Spi takes the values $0.270,0.105,0.105,0.270$ and 0.250 for Suburban, Regional, Inter-Regional, Inter-City and International services, respectively. These weights and services are only an example, as disclosing the real services provided by the Operator could be used to its identification.

\subsubsection{C3-Mobility:}

The complementary services and the offered transport conditions at a specific element should take into account the mobility regarding other transport modes (soft modes, 
highway, railway, sea, aerial, etc.). The connection with other services affects the station capacity and construction layout. This criterion takes into account the different services provided at each element. For each station a value of $\mathrm{C} 3$ is assigned based on the following equation:

$C 3_{i}=\sum M_{i}$

Where $M i$ takes the value 0.05 for soft modes, private cars or taxis; the value 0.15 for buses, trams or trains; and the value 0.20 for underground metro, boats or ferries.

\subsubsection{C4 - Significance:}

This criterion reflects the significance of each element according to its nature, and it is one of the most difficult criteria to define. However a few parameters could be defined to help verifying if the element gathers the necessary conditions to be labelled as significant for each predefined level, see examples in Table 1. For this work, five levels of significance were defined, namely: National, Regional, Touristic, Architectural and Network. For each station a value of $\mathrm{C} 4$ is assigned based on the following equation:

$$
C 4_{i}=\sum S_{i}
$$

\subsubsection{C5 - Location:}

This criterion takes into account the location of the element. The selected elements for this study are located in 12 municipalities of a selected part of Portugal. The value of this criterion is proportional to the population of each municipality and ranges from 1.0 to 0.0 for the highest population to the lowest population, respectively. The number of inhabitants for each municipality was taken from the national census of the year 2011 [12].

\subsubsection{Final score:}

Other criteria could be selected in this first step. Events such as large concerts, sports events or outdoor activities that imply a large number of people using a specific element 
at a specific time could lead to a different classification of the element. The dynamics of this process is an important feature and shows the relevance of "real time" monitoring. In order to achieve the final ranking score of each element in the network the following equation was applied:

$C_{i}=0.51 \times C 1+0.13 \times \mathrm{C} 2+0.13 \times \mathrm{C} 3+0.13 \times \mathrm{C} 4+0.10 \times \mathrm{C} 5$

Again, the weights selected for each criterion can be different according to the specific network under study or taking into account different selected criteria. It should be noted that the passenger flow is taken as the most important parameter, with about $50 \%$ of the weight.

These five criteria were applied to all elements of the network and a ranking score was achieved. An acceptable threshold should be defined by the team selected to perform the risk assessment, before proceeding with the analysis. Here, a threshold of 0.6 was selected, meaning that every element with this score and higher was taken to the next steps of the COUNTERACT process. Table 2 shows the individual scores for selected examples of elements in this network. As a result of this first step, 14 elements were selected with scores higher than 0.6.

\subsection{Probability of occurrence}

In this step, each element is linked to the selected threats. For the purpose of this study, only threats involving explosions were selected. Five levels were selected according to the capacity of the delivery system, namely: a) Suicide vest (9 kg TNT); b) Luggage (25 kg TNT); c) Car (500 kg TNT); d) Van (1 500 kg TNT); e) Truck (25 000 kg TNT).

The calculation of the probability of occurrence for each threat and each element implies a research on previous and similar attacks and attempts. COUNTERACT defines the probability of occurrence as a 5 level scale (Table 3) according to the frequency that the threat has been executed in their own or in other public transport operations [11]. Table 4 shows some examples of previous attacks on PT Operators after the year 2000 .

After crossing the information of previous attacks on similar PT Operators and their delivery systems, a value of Probability of Occurrence (Table 3) is assigned to each 
threat and for each element, with the results shown in Table 5. As can be seen the highest value for probability of occurrence is 3 . No threat has been executed within the own organization, but similar threats has been executed repeatedly within other PT Operators worldwide, including neighboring countries

\subsection{Severity of occurrence}

Impact/Severity stands for the damage to an asset arising from the execution of a threat, which is measured in escalating categories. COUNTERACT suggests a 4-level scale (Table 6), where the criteria for differentiation between the different levels focus mainly on the consequences of the various threats for persons, property and PT operator [11]. The final classification for the Impact would be the maximum of the three consequences.

In the case of consequences for persons, the impact value was estimated according to previous attacks with similar delivery systems and the number of passengers at peak time for each element. The consequences for property were estimated studying the layout of the element. For each element, a minimum standoff distance was established regarding each threat. As an example, it might be possible that a car, van or truck cannot get closer than several meters from a given element, while an armed vest can get close to most elements. It is possible to estimate the maximum overpressure resulting from an explosion according to the standoff distance of its charge using simple empirical equations available in [13][14], see Figure 2. Although the damage resulting from an explosion is dependent on the maximum pressure and its duration (impulse) it was considered enough, in order to simplify the analysis, to use the maximum pressure as a damage indicator. Later, when analyzing the elements with the highest associated risk, a more detail analysis should be performed. Reference charts, where pressure thresholds are presented for different construction materials, were used to estimate the damage on each element for each threat. Examples of these reference charts can be found in [15][16]. The consequences for the PT Operator were estimated according to previous attacks on similar size elements. Studying the time while the attacked PT Operators ceased functions on a similar size element due to similar threats, it is possible to have an estimation of the required time for this PT Operator. Following these premises the final consequences were determined for the elements under study, see Table 7. 


\subsection{Risk matrix}

The combination of Probability of Occurrence and Impact/Severity results in the Risk categories applying the following equation [11]:

Risk = Probability of Occurrence $\times$ Impact/Severity

COUNTERACT [11] suggests four risk categories according to their score (Table 8) and the subsequent required action.

With the scores for the Probability of Occurrence and the Severity of Occurrence is possible to plot the Risk Matrix shown in Table 9. Because the Portuguese PT Operator has no previous occurrences of attacks, there is no combination with disastrous classification. Some combinations scored a critical classification (8-12) due to similar attacks on neighboring countries and the respectively delivery systems (9-25 kg TNT), with easy "infiltration" and possibility to achieve low standoff distances.

This methodology is relatively easy to apply and provides the PT Operator with tools to quantify the relative risk for its elements. It must be kept in mind that this is a dynamic process and requires "real time" updates whenever there is a change in the network. As stated before, Risk Assessment in only one of the steps in the Risk Management model and the following step should be a detailed analysis of the highest risk elements, where prevention and mitigation measures would be studied. Comparing the risk values with and without those prevention and mitigation measures and the required investment costs, the PT Operator could make informed decisions on where and how to act. If a more detailed study on the structural behavior of a specific element is required, a structural safety assessment could be performed.

\section{Structural assessment for selected threats}

A structural security assessment was performed on one of the elements with the highest risk associated with the threats under study. The element in question is the element with the label "CF" which has risk levels of 12 for the luggage (25 kg TNT) and 8 for the van (1500 kg TNT). 
This element is a three-story building constructed in limestone stonework. This "L" shape building, see Figure 3a, is a high value element in the PT Operator, not only because of its effect on public opinion but due to its high passenger flow.

Two different scenarios (see Figure $3 b$ ) were studied in this analysis:

- Scenario A - corresponds to an explosion at a square on the South side of the building (at 4 meters from the building façade), as it is a place with possible high concentration of people due to the presence of outdoor cafes. The luggage size IED (25 kg TNT) was the selected delivery system for this scenario.

- Scenario B - corresponds to an explosion at the East façade of the building (at 5 meters from the center of the façade). The van size IED (1500 kg TNT) was the selected delivery system for this scenario. Another situation was analyzed Scenario B' - where the access to vehicles up until 25 meters from the East façade was closed. The same delivery system would still be possible, but only at 25 meters from the center of the façade.

\subsection{FEM model}

The FEM model was built in the ABAQUS software, where the Explicit solver was used. The definition of the geometric model was based on available drawings but without access to the detailed project of the building. This lack of information leads to some assumptions, especially regarding the pavements of the building.

Figure 4 shows the adopted geometry of the building. It is an "L" shaped building with around $2300 \mathrm{~m}^{2}$ per floor and external walls having a thickness of 1.0, 0.8 and $0.6 \mathrm{~m}$ for the $1^{\text {st }}, 2^{\text {nd }}$ and $3^{\text {rd }}$ floor, respectively. The stone columns are $0.8 \times 0.8 \mathrm{~m}^{2}$ and $0.4 \times 0.8 \mathrm{~m}^{2}$. The dimensions used to construct this model can be seen in Figure 4a. The story heights are about 7.7, 6.8 and $6.8 \mathrm{~m}$, from the ground level to the top (Figure $4 \mathrm{~b}$ ). The lower ends of the walls at the $1^{\text {st }}$ floor are considered fixed to the ground $(0.0 \mathrm{~m}$ level). Due to lack of information regarding the pavements of the building, different models were prepared, neglecting and considering the contribution of pavements.

The walls were modelled as shell elements and the columns were modelled as beam elements. The model was discretized in several parts creating a mesh (Figure 5). This mesh was automatically generated by ABAQUS, and then manipulated and controlled 
in order to obtain a good quality mesh. The walls are discretized with quadrilateral 4 nodes (S4R) and 3 nodes (S3R) shell elements. These are three-dimensional, isoparametric, doubly curved thin or thick shell element. These elements have five degrees of freedom at each node, reduced integration, hourglass control, and finite membrane strain [17]. The columns are discretized with 2-node linear beam elements (B31). The final mesh has 55936 elements; it is a rather fine mesh considering the size of the building. Shell elements were chosen to diminish the computational time requirements for the analyses.

\subsubsection{Material model}

The CDP (Concrete Damaged Plasticity) model used in ABAQUS software is a modification of the Drucker-Prager model by [18][19]. In particular, the shape of the failure surface in the deviatoric plane (Figure 6a) needs not to be a circle and it is governed by parameter Kc. This parameter can be interpreted as a ratio of the distances between the hydrostatic axis and, respectively, the compression meridian and the tension meridian in the deviatoric plane. This ratio is always higher than 0.5 and when it assumes the value 1 , the deviatoric cross section of the failure surface becomes a circle [20]. The CDP model requires four additional parameters to be defined: a) the dilatation angle; b) the flow potential eccentricity; c) the ratio of initial equibiaxial compressive yield stress to initial uniaxial compressive yield stress; and d) the viscosity parameter. For all these five parameters the default values suggested in ABAQUS User's Manual [17] were used (Table 10). Additional information regarding this material model can be found in [17]-[21].

The CDP model assumes that the failure for tensile cracking and compressive crushing of the material is characterized by damage plasticity. The model uses the concept of isotropic damage evolution in combination with isotropic tensile and compressive plasticity to represent the inelastic and fracture behaviour of the material. The model also allows the definition of strain hardening in compression and strain softening in tension. The adopted stress-strain curves in tension and compression can be seen in Figure $6 \mathrm{~b}$ and Figure $6 \mathrm{c}$, respectively, with exponential softening in tension and parabolic hardening, followed by exponential softening in compression. 
The mechanical properties for the masonry are presented in Table 11 and were collected from [22][23]. The data collected from these two sources corresponds to the static properties of limestone stonework (Static label). It should be noted that this kind of loading introduces high strain rates in the material. UFC 3-340-02 [24] suggests a DIF (Dynamic Increase Factor) of 1.19 for the compressive strength of masonry. However, other authors such as Hao and Tarasov [25] and Pereira et al [26] presented work where higher DIF values for masonry components were achieved, so another set of properties was introduced with a DIF of about 1.7 (DIF1.7 label). The DIF values are strain rate dependent [25][26], however in order to compare the results with the UFC 3-340-02 [24] the DIF values were considered constant in the present analyses.

As stated above, two different situations were considered for the pavements: a) neglecting the contribution of the pavements, meaning that the masonry panels are only constrained at ground level and at the connections with the other panels; and b) considering a generic pavement assuming perfect connections to the walls, introducing intermediate constrains at the masonry panels. This pavement is a reinforced concrete slab recent addition, modelled as elastic, with a Young's modulus of $30 \mathrm{GPa}$ and a density of $2400 \mathrm{~kg} / \mathrm{m} 3$.

\subsubsection{Blast loading}

In order to keep this problem as a pure Lagrangian formulation, the blast loading was defined as pressure profiles. Knowing the position and the weight, in TNT equivalent, it is possible to estimate the pressure profile acting on a specific surface using simple empirical equations [13][14]. Figure 7 shows the blast loading distribution for Scenario B. Due to the size of the East façade, three zones of loading were defined (L1, L2 and L3), each having different standoff distances (R1, R2 and R3). Regarding the North and South sides as well as the roof, the standoff distance was measured at one meter distance from the edge [14] into the surface itself, and the pressure profile was considered constant throughout the entire façade (L4). This same procedure was used to distribute the various loading profile for Scenario A and B'.

For a building with such large dimensions, the effects from both scenarios will be mostly localized. In order to decrease the computational time on the analysis, the whole 
structure was divided into two parts (Figure 8): a) Front section, regarding Scenario B and B'; and b) Side section, regarding Scenario A.

\subsection{Results from the explicit analysis}

ABAQUS Explicit was used to solve the non-linear equations of this problem. This software has been used successfully in previous situations regarding similar loading conditions [27][28] and similar materials [29][30]. This numerical model was calibrated previously using experimental results on masonry walls [31][32]. It must be noted that this analysis focuses only on the structural response of the building. Non-structural parts of the building, door frames, glazing systems, or occupants were not taken into consideration in the present analysis.

For this kind of analysis it is necessary to define a damage criterion that can be applied to categorize the damage on the masonry panels. UFC 3-340-02 [24] classifies the damage to unreinforced masonry walls according to the support rotation (Table 12). Other authors [33]-[35] state that collapse would occur if the maximum deflection reaches the wall thickness. Varma et al [34] reported a 4-level qualitative damage criterion based on observation of the wall. For the present work, the criteria defined by UFC 3-340-02 [24] will be applied, meaning that the support rotations will be checked in order categorize the damage on the masonry panels.

\subsubsection{Scenario A}

Scenario A corresponds to an explosion at a square on the South side of the building (Figure $3 b$ ). This is a place with possible high concentration of people due to the presence of outdoor cafes. An explosion with $25 \mathrm{~kg}$ TNT at 4 meters from a surface will create a reflected pressure of around 1.5 MPa with duration of $1.4 \mathrm{~ms}$ (Figure 9) on the panel closest to the explosion. The reflection angle was considered constant at $90^{\circ}$ for all panels.

Scenario A was studied with material properties labelled as UFC 3-340-02 (Table 11) and considering the contribution of pavements. As it will be shown, this scenario represents a low impact loading in the structure, and in order to easily see the results, only part of the structure (the closest part to the explosion), will be presented (Figure $10)$. 
Table 13 shows the time histories for the deformation and the maximum principal plastic strains for this part of the building. The panel on the left, which is closest to the explosion, is the first to be loaded. Then the blast wave reaches the panel on the right. At this time, the first panel is already unloaded and it is still moving due to the structure inertial forces. Although the structure has small displacements, the loading is enough to reach the nonlinear behavior of the masonry. As given in Table 13 there is a concentration of plastic strains on the right side of the panel on the left. Some cracking will occur in this part of the building, although it should be negligible.

This level of loading is very low for this structure. The closest panel to the explosion has a maximum displacement of around $2.75 \mathrm{~mm}$, keeping a $1.5 \mathrm{~mm}$ permanent displacement after the loading (Figure 11a). The analysis of the support rotations (Figure 11b) shows that these are still far away from the failure criteria described before. Although only the results from these two panels are shown, the rest of the structure was analyzed and, as we move further away from the explosion, the maximum deformation of each panel decreases. In fact, apart from the area described above where there is a concentration of plastic strains, the structure stay in its elastic regime.

\subsubsection{Scenario $B$}

Scenario B corresponds to an explosion at the East façade of the building, at 5 meters from the center of the façade (Figure 3b). This explosion with $1500 \mathrm{~kg}$ TNT will create a reflected pressure of around $34.5 \mathrm{MPa}$ with duration of $1.7 \mathrm{~ms}$ in the $\mathrm{L} 1$ region and around 2.5 $\mathrm{MPa}$ in the L2 region (Figure 12). Scenario B is a close-range large blast, and it will generate very high strain rates in the masonry, for this reason this scenario was studied with the material properties labelled as DIF1.7 (Table 11), which are assumed closer to the actual physical characteristics. Due to the presence of large span masonry panels, both situations regarding the pavements (neglecting and considering its contribution) were considered and the results were compared. Only the first $30 \mathrm{~ms}$ of analysis are presented here. Although being possible to capture the complete behavior of the structure, $30 \mathrm{~ms}$ are enough to reach the collapse of the structure considering the damage criteria defined previously.

Table 14 shows the evolution of deformation for this model. The global response of the structure changes if we neglect or consider the contribution of pavements. In the first 
case, the East facade panel behaves as one large masonry panel being supported at ground level and on its side edges. In the second case, considering the contribution of the pavements, the East façade behaves with intermediate supports along its height, similar to three "independent panels". Due to the dimensions of these panels (very long) it is almost as if they were only supported at the bottom and at the top.

The load resulting from this explosion is quite high and the structure response is quite fast. In the first $30 \mathrm{~ms}$ the masonry reaches a velocity of around $10 \mathrm{~m} / \mathrm{s}$ resulting in around $300 \mathrm{~mm}$ of maximum displacement in the L1 region after $30 \mathrm{~ms}$ (Figure 13). The difference, in the maximum displacement for the L1 region after $30 \mathrm{~ms}$, neglecting or considering pavements in the model is around $17 \%$. When we increase the distance from the explosion this difference increases.

Analyzing the support rotations (Figure 14) it is clear that, in both situations, the masonry panel rotates beyond the non-reusable state defined in UFC-3-340-02 [24]. At this point, it was considered that this part of the structure would have collapsed. The contribution of pavements in the model leads to lower values of rotations at ground level (Figure 14b). However, the behavior of the panel in the first floor is closer to oneway yield pattern which lowers the limit to $1.0^{\circ}$.

Table 15 shows the evolution of the maximum principal plastic strains. In both cases the collapse would occur close to the boundaries of the L1 region. The supports at ground level sustain high levels of strains in both cases, but considering pavements, the area at the 2nd floor pavement also presents itself with large plastic strains. This is due to the intermediate support originated by that pavement. This scenario would have resulted in collapse of the structure due to the failure of the central supporting wall.

\subsubsection{Scenario B'}

Scenario B' corresponds to an explosion at the East façade of the building, at 25 meters from the center of the façade (Figure $3 b$ ). This simulates the possibility of closing to traffic the road right in front of this façade and the application of bollards preventing vehicles to get closer to the building. This explosion with $1500 \mathrm{~kg}$ TNT will create a reflected pressure of around $0.45 \mathrm{MPa}$ with duration of $9.5 \mathrm{~ms}$ in the L1 region (Figure $15)$. 
In this scenario all three sets of material properties were studied and compared, neglecting and considering the pavements contribution. Table 16 and Table 17 show the evolution of deformation and the maximum principal plastic strains, neglecting and considering the contribution of pavements. These results were plotted with the material properties labelled as DIF1.7. The behavior of the masonry panels is similar to the one observed in Scenario B. Without pavements, the east façade behaves as one large masonry panel supported at ground level and on its sides. With pavements, it is clear the "independent panel" behavior at the 3rd floor (Table 17).

Figure 16 shows the displacement in the L1 region and at 3rd floor. The behavior for both possibilities regarding pavements is different. In the first case (Figure 16a) the maximum displacement at 3rd floor is achieved at around 0.75 seconds after the blast wave reaching the structure while in the second case (Figure 16b) the maximum displacement at $3 \mathrm{rd}$ floor is reached at around $0.055 \mathrm{~s}$ after the arrival of the blast wave.

In both models the support rotations (Figure 17) are kept under the Reusable limit established by UFC-3-340-02 [24]. In the model considering the contribution of pavements an additional point was analyzed. As can be seen in Table 16 the maximum displacement will take place in the 3rd floor, meaning that the maximum rotation is at the 3rd floor level. This last rotation is still under the reusable limit (Figure 17b). Although it is not shown here, the rotations at the side edges of the East façade were also analyzed and its value are also under safe levels.

The distribution of stresses and strains for both models is quite different. Table 16 and Table 17 show the maximum principal plastic strains for both models. While in the model neglecting the contribution of pavements there is a concentration of plastic strain at ground level, along the horizontal support (Table 16), in the other model that is not observed. In the second model, because the maximum deformation occurs at the 3rd floor, there is a concentration of plastic strain at the 3rd floor mid-level (Table 17).

In order to evaluate the influence of the suggested material properties, a comparison was made and the results can be seen in Figure 18. As expected the maximum displacement is achieved with the static properties. The maximum displacement with DIF1.7, which represents an increase of $70 \%$ in the strength and modulus of the material, is around $68 \%$ of the static reference. The dynamic increase factor suggested by UFC 3-340-02 [24] leads to a maximum displacement of around $92 \%$ of the static reference. As 
expected, the selection of material properties has a large influence on the structural response. Studies on the dynamic mechanical properties of masonry are still not easily found in the open literature and the suggested DIF values on the available standards seem to be excessively conservative [25][26].

\section{Conclusions}

A risk assessment model for public transport networks was applied to a case study in a Portuguese region and the elements with the highest risk due to external explosions were identified. The COUNTERACT methodology, due to the dynamic nature of transportation networks, require "real time" monitoring as any changes in the network could lead to a different risk matrix.

From the highest risk group, one element was selected for a detailed analysis. This structure was modelled using explicit non-linear dynamics and the results were presented for different explosion scenarios. It was shown that a small package explosion would have a small impact on the structure while a large package explosion would lead to the collapse of the structure. Increasing the standoff distance, as a measure for mitigating the impact of the explosion, was analysed and proven to be an effective measure, according to the obtained results. This measure is especially important when dealing with historical masonry construction where structural strengthening is difficult generally due to the historical and cultural value of the structure.

A comparison was also made for different material properties. Selecting the material properties has a major role, due to the large impact on the final results. If possible, in situ assessment of material properties should take place to properly grasp the condition of existing buildings. Recent research, suggests that the available codes could be excessively conservative regarding the dynamic increase factor for material properties.

\section{Acknowledgements}

This work was performed under Project CH-SECURE, with reference PTDC/ECM/120118/2010, funded by the Portuguese Foundation of Science and Technology - FCT. The authors acknowledge the support. The first author also 
acknowledges the support from his $\mathrm{PhD}$ FCT grant with the reference SFRH/BD/45436/2008.

\section{References}

[1] DoS (Department of State), Country reports on terrorism. U. S. Department of State, Office for Counterterrorism, USA, 2007.

[2] United Nations, Security Council Resolution 1566, 2004.

[3] TTSRL, Concepts of terrorism: analysis of the rise, decline, trends and risk, Transnational Terrorism EU Project, Deliverable 5, 2008.

[4] NCC (National Counterterrorism Centre), Report on terrorism 2011. Office of the Director of National Intelligence, USA, 2012.

[5] Homeland Security, Risk management fundamentals. Department of Homeland Security, USA, 2011.

[6] FEMA 452, Risk assessment. Federal Emergency Management Agency, USA, 2005.

[7] ISO 31000, Risk management - principals and guidelines. International Standards, 2009.

[8] Danish Emergency Management Agency (DEMA), DEMA's approach to risk and vulnerability analysis for civil contingency planning. The RVA model, 2006.

[9] UFC 4-020-01, Security Engineering Facilities Planning Manual, Department of Defence, USA, 2008.

[10] Muhlhausen, D.B., McNeil, J.B., Terror trends: 40 years' data on international and domestic terrorism. The Heritage Foundation, special report \#93, 2011.

[11] COUNTERACT, Generic guidelines for conducting risk assessment in public transport networks - final report. COUNTERACT Deliverable 3-Pt4, 2006.

[12] Instituto Nacional de Estatística (INE), Census 2011 (in Portuguese). Instituto Nacional de Estatística, Portugal, 2012.

[13] Bangash, M.Y.H., Bangash, T., Explosions - resistant buildings: design, analysis, and case studies. Springer Publications, Germany, 2006.

[14] Cormie, D., Mays, G.C., Smith, P.D., Blast effects on buildings, 2nd edition. Thomas Telford Publications, England, 2009.

[15] FEMA 426, Reference manual to mitigate potential terrorist attacks against buildings. Federal Emergency Management Agency, USA, 2003. 
[16] Elsayed, N.M., Atkins, J.L., Explosion and blast-related injuries, Elsevier Publications, China, 2008.

[17] ABAQUS User Manual, Dassault Systemes Simulia Corporation Springer, USA, 2010.

[18] Lubliner, J., Oliver, J., Oller, S., Onate, E., A plastic-damage model for concrete. International Journal of Solids and Structures, 1989, 25(3), pp. 299-329.

[19] Lee, J., Fenves, G.L., Plastic-damage model for cyclic loading of concrete structures. Journal of Engineering Mechanics, 1998, 124 (8), pp. 892-900.

[20] Kmiecik, P., Kaminski, M., Modelling of reinforced concrete structures and composite structures with concrete strength degradation taken into consideration. Archives of Civil and Mechanical Engineering, 2011, 11(3), pp. 623-636.

[21] Jankowiak, T., Lodygowski, T., Identification of parameters of concrete damage plasticity constitutive model. Foundations of Civil and Environmental Engineering, 2005, 6(1), pp 53-69.

[22] Oliveira, C.S., Seismic vulnerability of historical constructions: a contribution. Bulletin of Earthquake Engineering, 2003, 1(1), pp. 37-82.

[23] Tassios, T.P., Seismic engineering of monuments. Bulletin of Earthquake Engineering, 2010, 8(6), pp. 1231-1265.

[24] UFC 3-340-02, Structures to resist the effects of accidental explosions. Department of Defence, USA, 2008.

[25] Hao, H., Tarasov, B.G., Experimental study of dynamic material properties of clay brick and mortar at different strain rates. Australian Journal of Structural Engineering, 2008, 8(2), pp. 117-132.

[26] Pereira, J.M., Security Evaluation and Design of Structures Subjected to Blast Loading, PhD Thesis, University of Minho, Portugal, 2014.

[27] Jacinto, A.C., Ambrosini, R.D., Danesi, R.F., Experimental and computational analysis of plates under air blast loading. International Journal of Impact Engineering, 2001, 25(10), pp. 927-947.

[28] Heidarpour, A., Bradford, M.A., Liu, J., Steel arches subjected to blast loading: a non-discretization analysis approach. Applied Mathematical Modelling, 2012, 36(9), pp. 3971-3984.

[29] Zheng, Y., Taylor, S., Robinson, D., Nonlinear finite element analysis of masonry arch bridges reinforced with FRP. In Proc. of the 6th International Conference on Arch Bridges - ARCH'10, China, 2010. 
[30] Al-Gohi, B.H., Demir, C., Ilki, A., Baluch, M.H., Rahman, M.K., Al-Gadhib, A.H., Seismic vulnerability of multi-leaf heritage masonry walls using elastoplastic damage model. In Proc. of the International Workshop: Role of research infrastructure in seismic rehabilitation, Turkey, 2012.

[31] Pereira, J.M., Campos, J., Lourenço, P.B., Experimental study on masonry infill walls under blast loading. In Proc. of the 9th International Masonry Conference, Portugal, 2014.

[32] Pereira, J.M., Campos, J., Lourenço, P.B., Masonry infill walls under blast loading using confined underwater blast wave generators (WBWG). In Proc. of the 8th International Conference on Analytical Models and New Concepts in Concrete and Masonry Structures, Poland, 2014.

[33] Doherty, K., Griffith M.C., Lam, N., Wilson, J., Displacement-based seismic analysis for out-of-plane bending of unreinforced masonry walls. Earthquake Engineering \& Structural Dynamics, 2002, 31(4), pp 833-850.

[34] Zapata, B.J., Weggel, D.C., Collapse study of an unreinforced masonry gearing wall building subjected to internal blast loading. Journal of Performance of Constructed Facilities, 2008, 22(2), pp. 92-100.

[35] UFC 3-340-01, Design and analysis of hardened structures to conventional weapons effects (FOUO). Department of Defence, USA, 2002.

[36] Varma, R., Tomar, C., Parkash, S., Sethi, V., Damage to brick masonry panel walls under high explosive detonations. ASME Publications, 1996, 351, pp. 207216. 


\section{TABLES:}

Table 1: Significance justification parameters.

\begin{tabular}{cl}
\hline Significance & \multicolumn{1}{c}{ Justification parameters } \\
\hline \multirow{2}{*}{ National } & $\begin{array}{l}\text { Highlighted element with a high hierarchical national level. Placed with special } \\
\text { relevance as an image of the Portuguese transport network for the Portuguese and } \\
\text { foreigner passenger. }\end{array}$ \\
\hline Regional & $\begin{array}{l}\text { Highlighted element at regional level. Placed with special relevance as representative } \\
\text { of its region. } \\
\text { An element with National significance has cumulatively Regional significance. } \\
\text { Also applies if the element is in a district capital. }\end{array}$ \\
\hline \multirow{2}{*}{ Touristic } & $\begin{array}{l}\text { Element with particular interest from the tourist point of view as it provides } \\
\text { accessibility to the tourist area in which it operates. }\end{array}$ \\
& $\begin{array}{l}\text { Element belonging to a particular transport route with a touristic character. } \\
\text { Connections with touristic routes, namely with other transport modes. }\end{array}$ \\
\hline \multirow{2}{*}{ Network } & $\begin{array}{l}\text { Element with recognised historical and architectural significance. } \\
\text { Element with relevant aesthetics or cultural elements. }\end{array}$ \\
\hline & $\begin{array}{l}\text { Element with unique conditions or services regarding an operational point of view. } \\
\text { Element with historic value regarding the development of the national network. }\end{array}$ \\
\hline
\end{tabular}


Table 2: Selected examples of key infrastructures scores.

\begin{tabular}{lccccccc}
\hline$\#$ & Element & $\boldsymbol{C 1}$ & $\boldsymbol{C} \boldsymbol{C}$ & $\boldsymbol{C 3}$ & $\boldsymbol{C 4}$ & $\boldsymbol{C 5}$ & $\boldsymbol{C}$ \\
\hline 10 & AJ & 0.78 & 0.23 & 0.20 & 0.00 & 0.30 & $\boldsymbol{0 . 4 9}$ \\
\hline 15 & AO & 0.68 & 0.88 & 0.20 & 0.15 & 0.37 & $\mathbf{0 . 5 4}$ \\
\hline 17 & AQ & 0.78 & 0.23 & 0.20 & 0.15 & 0.37 & $\mathbf{0 . 5 1}$ \\
\hline 23 & AX & 0.18 & 0.23 & 0.12 & 0.04 & 1.00 & $\mathbf{0 . 2 9}$ \\
\hline 30 & BD & 0.43 & 0.23 & 0.12 & 0.00 & 0.36 & $\mathbf{0 . 3 2}$ \\
\hline 35 & BI & 0.75 & 0.65 & 0.2 & 0.15 & 0.24 & $\mathbf{0 . 5 4}$ \\
\hline 43 & BQ & 0.01 & 0.10 & 0.12 & 0.15 & 0.68 & $\mathbf{0 . 1 2}$ \\
\hline 46 & BT & 0.01 & 0.20 & 0.12 & 0.15 & 0.12 & $\boldsymbol{0 . 0 8}$ \\
\hline 58 & CF & 1.00 & 0.23 & 0.60 & 1.00 & 1.00 & $\mathbf{0 . 8 5}$ \\
\hline 62 & CJ & 0.89 & 0.23 & 0.20 & 0.60 & 0.31 & $\mathbf{0 . 6 2}$ \\
\hline
\end{tabular}


Table 3: Probability of occurrence [11].

\begin{tabular}{ccl}
\hline $\begin{array}{c}\text { Very } \\
\text { High }\end{array}$ & $\mathbf{5}$ & $\begin{array}{l}\text { The threat can be executed at any time and/or has been executed within the } \\
\text { organization repeatedly. }\end{array}$ \\
\hline High & $\mathbf{4}$ & $\begin{array}{l}\text { It has to be reckoned with the threat being executed repeatedly. The threat has been } \\
\text { executed within the own organization once. }\end{array}$ \\
\hline Possible & $\mathbf{3}$ & $\begin{array}{l}\text { An execution of the threat has to be reckoned with. The threat has been executed } \\
\text { repeatedly within other PT operations world-wide, or at least once within a PT } \\
\text { operation in the own/ neighbouring country. }\end{array}$ \\
\hline Low & $\mathbf{2}$ & $\begin{array}{l}\text { The threat is executed rarely, but has been executed in isolated cases in other } \\
\text { organizations (world-wide). }\end{array}$ \\
\hline $\begin{array}{c}\text { Very } \\
\text { Unlikely }\end{array}$ & $\mathbf{1}$ & $\begin{array}{l}\text { An execution of the threat is extremely unlikely, and the threat has never been } \\
\text { executed in other PT operations before. }\end{array}$ \\
\hline
\end{tabular}


Table 4: Examples of previous terrorist attacks on PT Operators using explosives.

\begin{tabular}{lccl}
\hline Place & Year & Fatalities & \multicolumn{1}{c}{ Description } \\
\hline Angola & 2001 & 252 & $\begin{array}{l}\text { Used an explosive device to derail a train and attack the } \\
\text { passengers with fire weapons. }\end{array}$ \\
\hline Refiganj, India & 2002 & 130 & Derail a trail over a bridge. \\
\hline $\begin{array}{l}\text { Stavropol Krai, } \\
\text { Russia }\end{array}$ & 2003 & 46 & Suicide bomber in a train. \\
\hline Moscow, Russia & 2004 & 41 & Suicide bomber at the subway station Avtozavodskaya. \\
\hline Madrid, Spain & 2004 & 191 & Several explosions in the railway system. \\
\hline London, UK & 2005 & 56 & Three explosions at subway stations and one explosion in a bus. \\
\hline Mumbai, India & 2006 & 209 & Several explosions in the suburban system. \\
\hline Moscow, Russia & 2010 & 40 & $\begin{array}{l}\text { Two suicide bombers at subway stations, Lubyanka and Park } \\
\text { Kultury. }\end{array}$ \\
\hline Moscow, Russia & 2011 & 35 & Suicide bomber at Domodedovo airport. \\
\hline
\end{tabular}


Table 5: Probability of occurrence for the PT Operator.

\begin{tabular}{lcccccc}
\hline$\#$ & Element & Vest & Luggage & Car & Van & Truck \\
\hline 1 & AA & 3 & 3 & 2 & 2 & 1 \\
\hline 5 & AE & 3 & 3 & 2 & 2 & 1 \\
\hline 19 & AS & 3 & 3 & 2 & 2 & 1 \\
\hline 20 & AT & 3 & 3 & 2 & 2 & 1 \\
\hline 21 & AU & 3 & 3 & 2 & 2 & 1 \\
\hline 22 & AV & 3 & 3 & 2 & 2 & 1 \\
\hline 25 & AY & 3 & 3 & 2 & 2 & 1 \\
\hline 27 & BA & 3 & 3 & 2 & 2 & 1 \\
\hline 58 & CF & 3 & 3 & 2 & 2 & 1 \\
\hline 59 & CG & 3 & 3 & 2 & 2 & 1 \\
\hline 62 & CJ & 3 & 3 & 2 & 2 & 1 \\
\hline 66 & CO & 3 & 3 & 2 & 2 & 1 \\
\hline 72 & CU & 1 & 1 & 1 & 1 & 1 \\
\hline 73 & CV & 1 & 1 & 1 & 1 & 1 \\
\hline & & & & & &
\end{tabular}


Table 6: Impact/Severity [11].

\begin{tabular}{cclll}
\hline Disastrous & $\mathbf{4}$ & $\begin{array}{c}\text { Consequences for } \\
\text { Persons }\end{array}$ & $\begin{array}{l}\text { Consequences for } \\
\text { Property/Environment } \\
\text { numerous severe injuries }\end{array}$ & $\begin{array}{l}\text { Consequences for PT } \\
\text { Operator and Services }\end{array}$ \\
\hline Critical & $\mathbf{3}$ & $\begin{array}{l}\text { Low number of deaths } \\
\text { and/or severely injured }\end{array}$ & $\begin{array}{l}\text { Severe damage to property } \\
\text { property and/or } \\
\text { environment }\end{array}$ & $\begin{array}{l}\text { Loss of vital functions } \\
\text { and/or operation over a short }\end{array}$ \\
\hline Marginal & $\mathbf{2}$ & $\begin{array}{l}\text { Light casualties } \\
\text { and/or operation over a long } \\
\text { period of time }\end{array}$ & $\begin{array}{l}\text { period of time } \\
\text { potable damage to } \\
\text { property and/or } \\
\text { environment }\end{array}$ & $\begin{array}{l}\text { Minor impact on functions } \\
\text { and/or operation. }\end{array}$ \\
\hline Uncritical & $\mathbf{1}$ & $\begin{array}{l}\text { Possibility of few light } \\
\text { casualties }\end{array}$ & $\begin{array}{l}\text { Small damage to property } \\
\text { and/or environment }\end{array}$ & $\begin{array}{l}\text { No impact on functions } \\
\text { and/or operation }\end{array}$ \\
\hline
\end{tabular}


Table 7: Severity of occurrence for the PT Operator.

\begin{tabular}{|c|c|c|c|c|c|c|c|c|c|c|c|c|c|c|c|}
\hline \multirow[b]{2}{*}{ Element } & \multicolumn{3}{|c|}{ Vest } & \multicolumn{3}{|c|}{ Luggage } & \multicolumn{3}{|c|}{ Car } & \multicolumn{3}{|c|}{ Van } & \multicolumn{3}{|c|}{ Truck } \\
\hline & 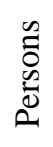 & 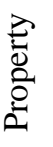 & 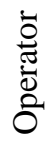 & 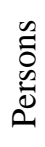 & $\begin{array}{l}\overrightarrow{0} \\
\text { o. } \\
\text { D. }\end{array}$ & 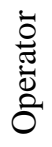 & 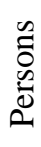 & 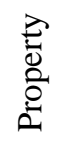 & 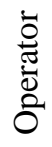 & 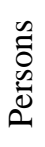 & 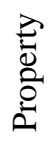 & 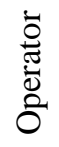 & $\begin{array}{l}0 \\
0 \\
0 \\
0 \\
0 \\
0\end{array}$ & $\begin{array}{l}\overrightarrow{0} \\
\text { D. } \\
\text { : } \\
\text { : }\end{array}$ & 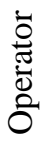 \\
\hline AA & 3 & 1 & 1 & 4 & 2 & 2 & 3 & 3 & 2 & 3 & 3 & 3 & 4 & 4 & 4 \\
\hline $\mathrm{AE}$ & 2 & 1 & 1 & 3 & 2 & 2 & 3 & 3 & 2 & 3 & 3 & 2 & 3 & 4 & 3 \\
\hline AS & 2 & 1 & 1 & 3 & 2 & 2 & 3 & 2 & 2 & 3 & 2 & 2 & 3 & 3 & 3 \\
\hline AT & 3 & 1 & 1 & 3 & 2 & 2 & 3 & 2 & 2 & 3 & 3 & 2 & 3 & 4 & 3 \\
\hline $\mathrm{AU}$ & 3 & 1 & 1 & 4 & 2 & 2 & 3 & 3 & 2 & 3 & 3 & 2 & 4 & 4 & 3 \\
\hline $\mathrm{AV}$ & 2 & 1 & 1 & 3 & 2 & 2 & 3 & 2 & 2 & 3 & 2 & 2 & 3 & 3 & 3 \\
\hline AY & 2 & 1 & 1 & 3 & 2 & 2 & 3 & 2 & 2 & 3 & 3 & 3 & 3 & 4 & 4 \\
\hline BA & 3 & 1 & 1 & 3 & 2 & 2 & 3 & 3 & 3 & 3 & 4 & 3 & 4 & 4 & 4 \\
\hline $\mathrm{CF}$ & 3 & 1 & 1 & 4 & 2 & 2 & 3 & 3 & 2 & 3 & 4 & 2 & 4 & 4 & 2 \\
\hline CG & 2 & 1 & 1 & 3 & 2 & 2 & 3 & 3 & 2 & 3 & 3 & 2 & 3 & 4 & 3 \\
\hline CJ & 3 & 1 & 1 & 4 & 2 & 2 & 3 & 3 & 2 & 3 & 3 & 2 & 3 & 4 & 3 \\
\hline $\mathrm{CO}$ & 3 & 1 & 1 & 4 & 2 & 2 & 3 & 3 & 3 & 3 & 3 & 2 & 4 & 4 & 3 \\
\hline $\mathrm{CU}$ & 2 & 1 & 3 & 2 & 2 & 3 & 1 & 2 & 3 & 2 & 3 & 4 & 2 & 4 & 4 \\
\hline $\mathrm{CV}$ & 2 & 1 & 2 & 2 & 2 & 2 & 1 & 2 & 2 & 2 & 3 & 3 & 2 & 4 & 3 \\
\hline
\end{tabular}


Table 8: Risk categories [11].

\begin{tabular}{lcl}
\hline Categories & Score & \multicolumn{1}{c}{ Action Required } \\
\hline Intolerable & $15-20$ & Must be avoided or Impact must be mitigated as far as possible \\
\hline Precarious & $8-12$ & $\begin{array}{l}\text { Shall only be accepted if the efforts for prevention and/or mitigation of } \\
\text { impact is unreasonably high }\end{array}$ \\
\hline Tolerable & $4-6$ & Shall be accepted, but threat needs to be assessed regularly \\
\hline Negligible & $1-3$ & Shall be accepted \\
\hline
\end{tabular}


Table 9: Risk matrix for the PT Operator.

\begin{tabular}{cc|c|c|c|c|c|}
\hline$\#$ & Element & Vest & Luggage & Car & Van & Truck \\
\hline 1 & AA & 9 & 12 & 6 & 6 & 4 \\
\hline 5 & AE & 6 & 9 & 6 & 6 & 4 \\
\hline 19 & AS & 6 & 9 & 6 & 6 & 3 \\
\hline 20 & AT & 9 & 9 & 6 & 6 & 4 \\
\hline 21 & AU & 9 & 12 & 6 & 6 & 4 \\
\hline 22 & AV & 6 & 9 & 6 & 6 & 3 \\
\hline 25 & AY & 6 & 9 & 6 & 6 & 4 \\
\hline 27 & BA & 9 & 9 & 6 & 8 & 4 \\
\hline 58 & CF & 9 & 12 & 6 & 8 & 4 \\
\hline 59 & CG & 6 & 9 & 6 & 6 & 4 \\
\hline 62 & CJ & 9 & 12 & 6 & 6 & 4 \\
\hline 66 & CO & 9 & 12 & 6 & 6 & 4 \\
\hline 72 & CU & 3 & 3 & 3 & 4 & 4 \\
\hline 73 & CV & 2 & 2 & 2 & 3 & 4 \\
\hline
\end{tabular}


Table 10: Default parameters of the CDP model [17].

\begin{tabular}{rc}
\hline \multicolumn{1}{c}{ Parameter } & Value \\
\hline Dilatation angle $(\Psi)$ & $20^{\circ}$ \\
\hline Eccentricity $(\varepsilon)$ & 0.1 \\
\hline$f_{b o} \alpha f_{c 0}$ & 1.16 \\
\hline$K_{c}$ & 0.667 \\
\hline Viscosity parameter $(\mu)$ & 0.0
\end{tabular}


Table 11: Mechanical properties ( $\sigma_{t 0}$ is the tensile strength, $\sigma_{c 0}$ is the elastic limit of the uniaxial compressive stress, $\sigma_{c u}$ is the compressive strength, $E_{0}$ is the Young's modulus and $\rho$ is the specific weight).

\begin{tabular}{rccc}
\hline Parameter & Static & UFC-3-340-02 & DIF1.7 \\
\hline$\sigma_{t 0}[\mathrm{MPa}]$ & 0.2 & 0.2 & 0.4 \\
\hline$\sigma_{c 0}[\mathrm{MPa}]$ & 4.5 & 5.2 & 7.5 \\
\hline$\sigma_{c u}[\mathrm{MPa}]$ & 6.0 & 7.0 & 10.0 \\
\hline$E_{0}[\mathrm{GPa}]$ & 4.5 & 4.5 & 7.5 \\
\hline$\rho\left[\mathrm{kN} / \mathrm{m}^{3}\right]$ & 24 & 24 & 24 \\
\hline
\end{tabular}


Table 12: Unreinforced masonry damage criteria [24].

\begin{tabular}{rcc}
\hline Element & Yield pattern & Maximum support rotation \\
\hline \multirow{2}{*}{ Masonry Reusable } & One-way & $0.5^{\circ}$ \\
\cline { 2 - 3 } & Two-way & $0.5^{\circ}$ \\
\hline \multirow{2}{*}{ Masonry Non-reusable } & One-way & $1.0^{\circ}$ \\
\cline { 2 - 3 } & Two-way & $2.0^{\circ}$ \\
\hline
\end{tabular}


Table 13: Time histories for scenario A: deformed mesh and location of the maximum principal plastic strains.

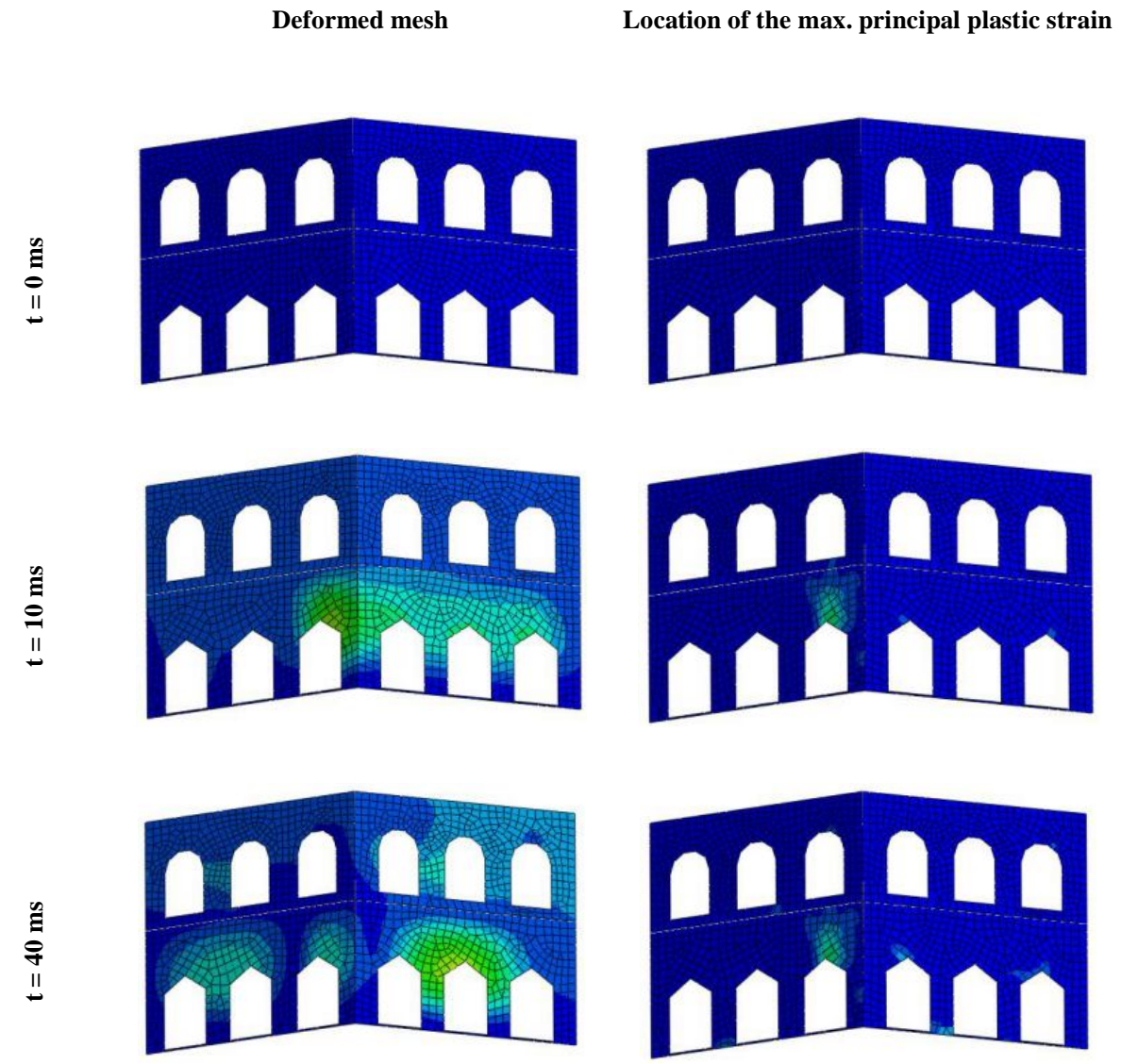


Table 14: Deformed mesh time history for scenario B: with and without pavements.
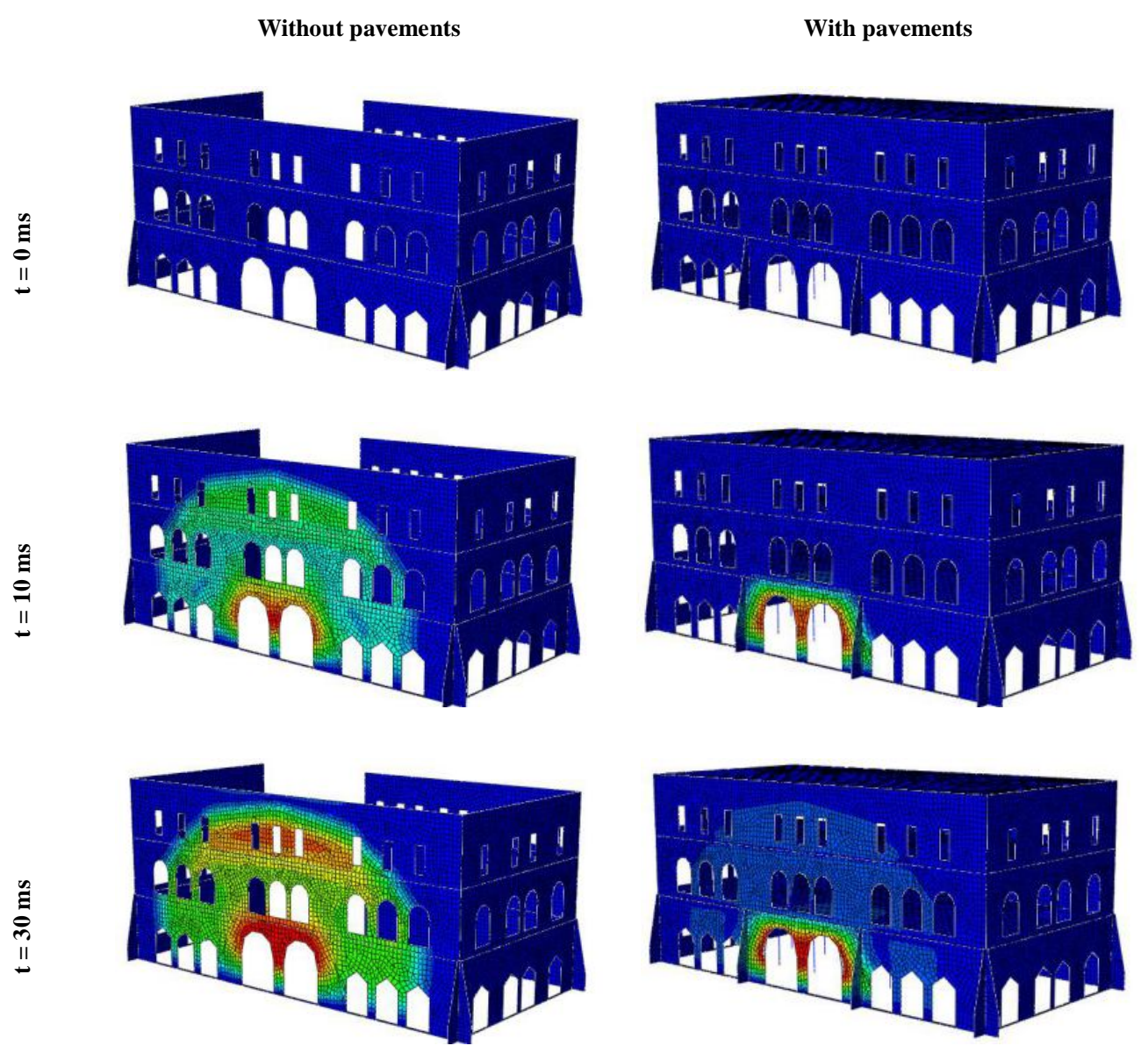
Table 15: Time history of the location of the maximum principal plastic strains for scenario B: with and without pavements.
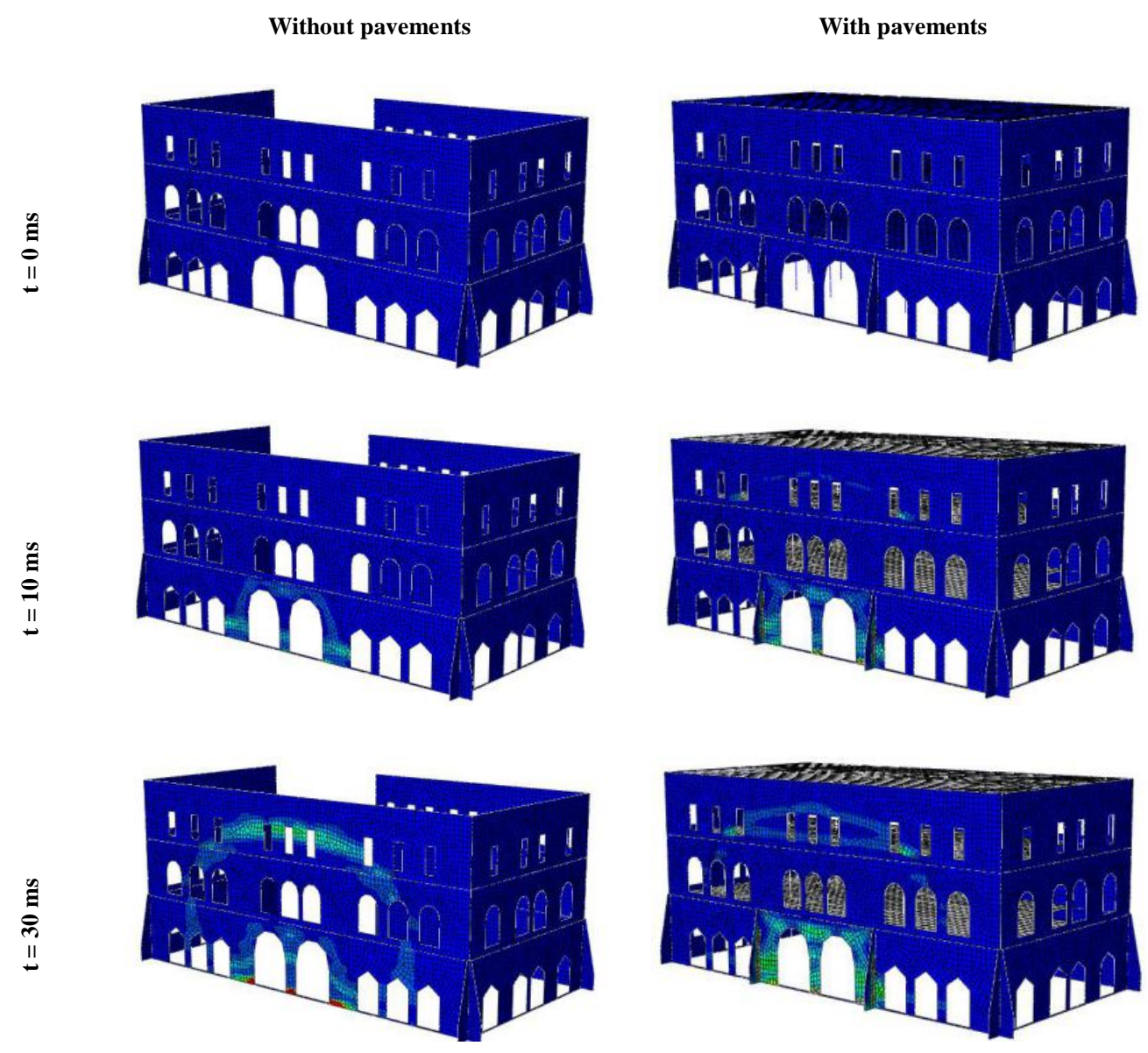
Table 16: Scenario B' neglecting pavements: deformed mesh and location of the maximum principal strains.
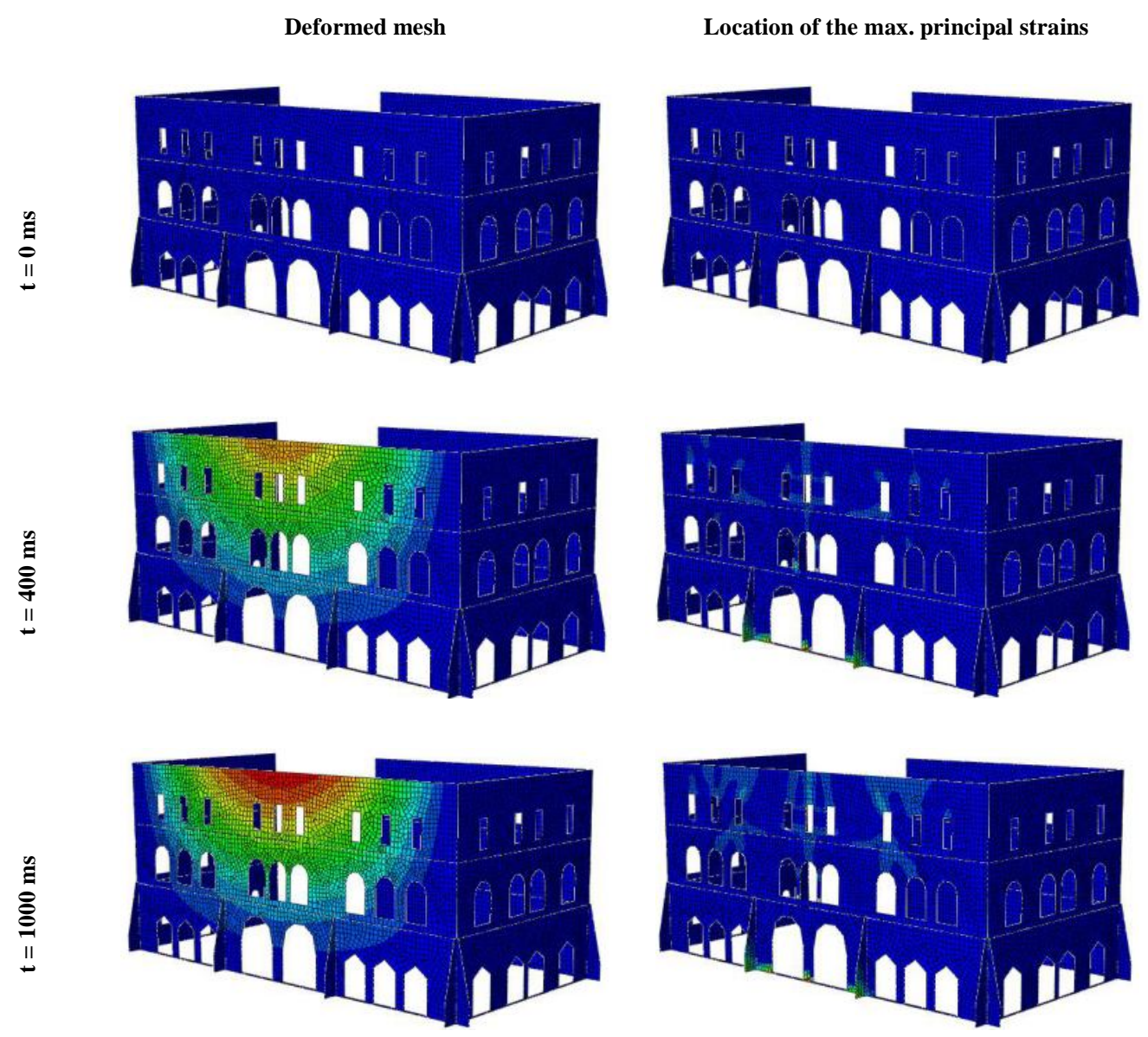
Table 17: Scenario B' considering pavements: deformed mesh and location of the maximum principal strains.

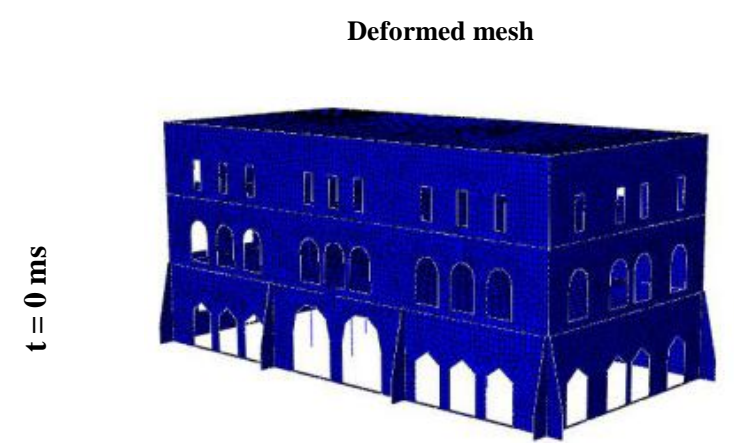

$$
\text { Location of the max. principal strains }
$$
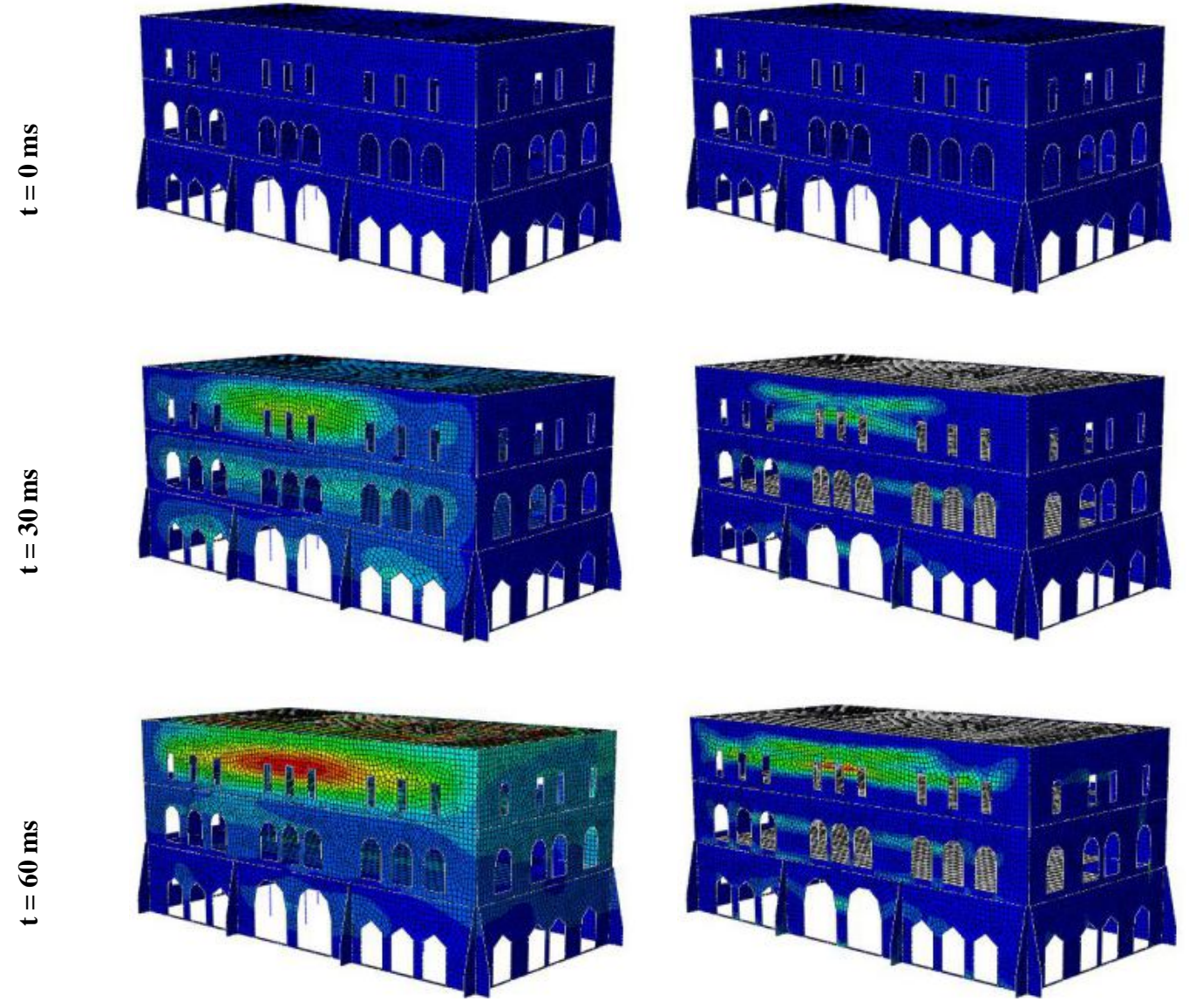


\section{FIGURES:}

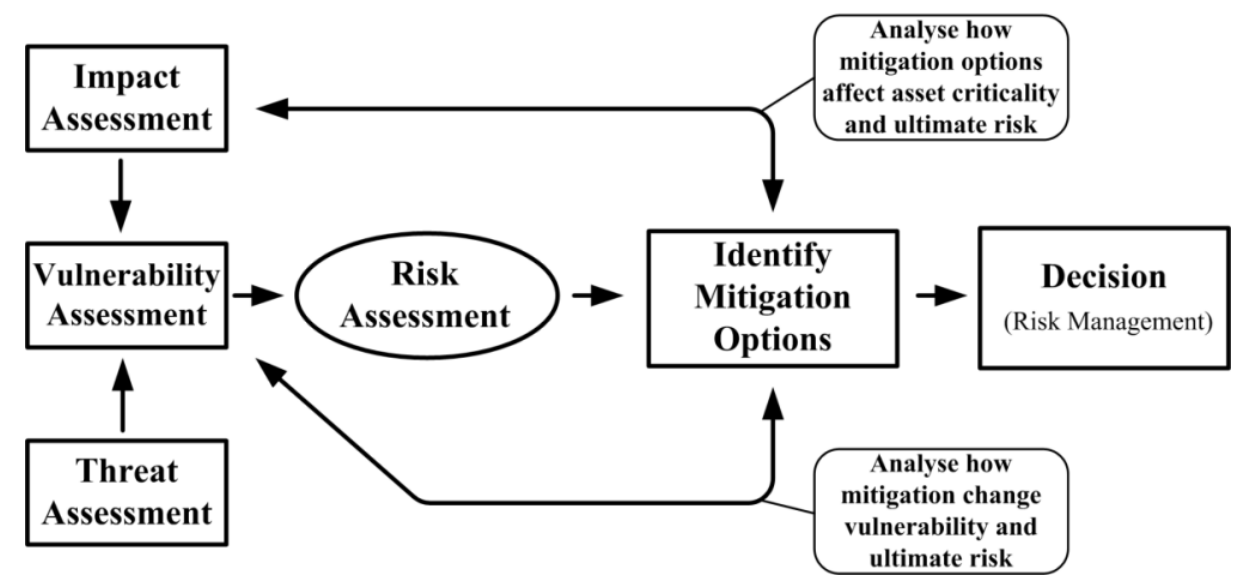

Figure 1: Risk management model. 


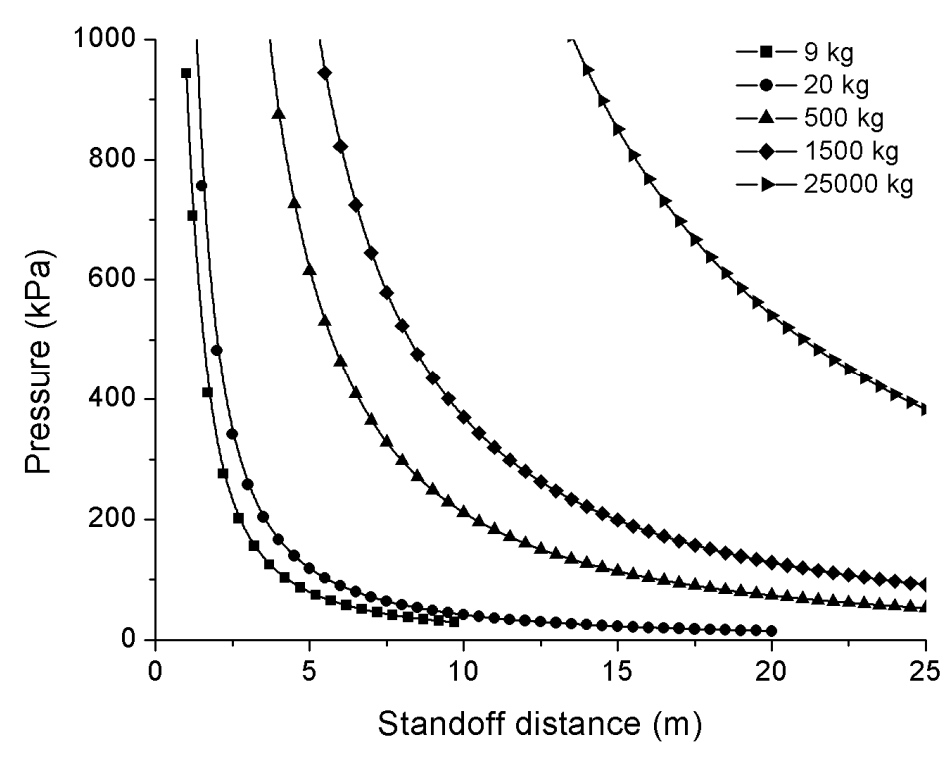

Figure 2: Maximum pressure as a function of the standoff distance. 


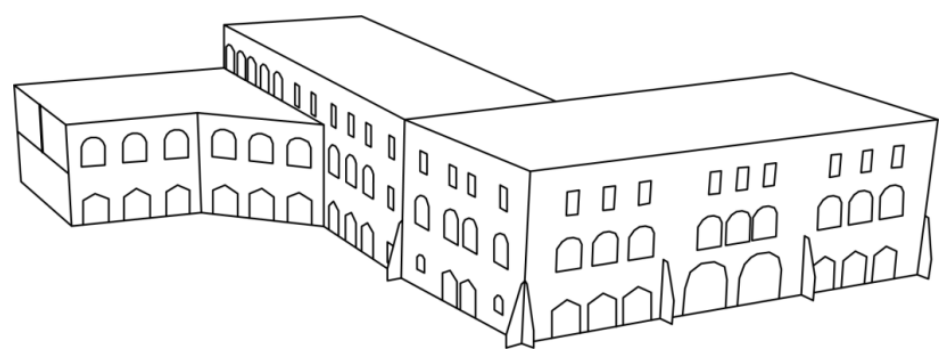

a)

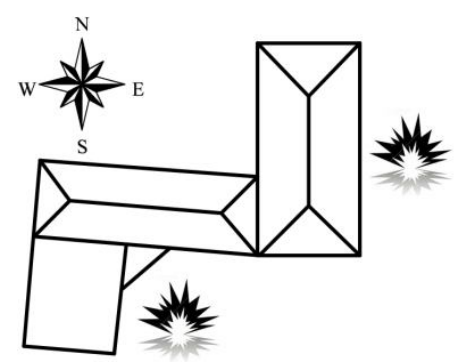

b)

Figure 3: Element "CF": a) building schematics; b) scenarios under study. 


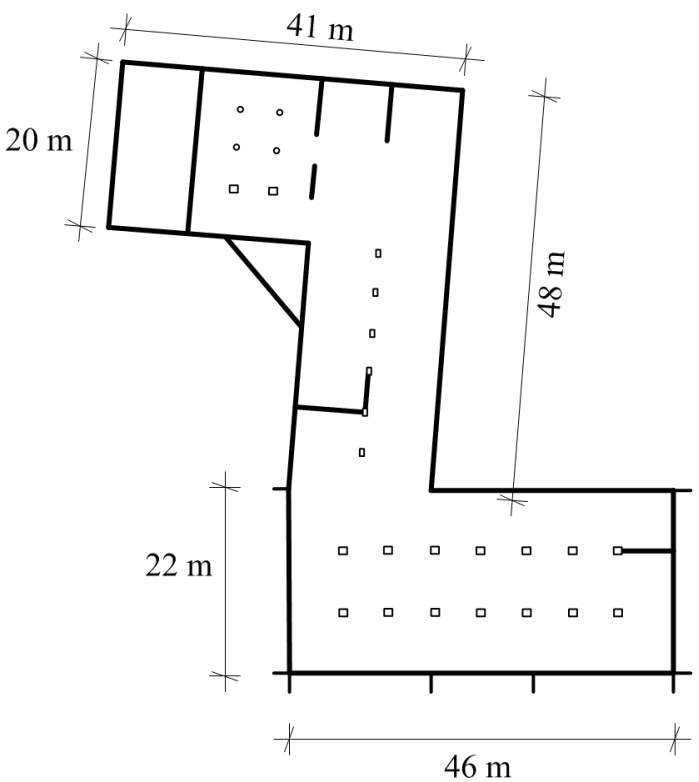

a)

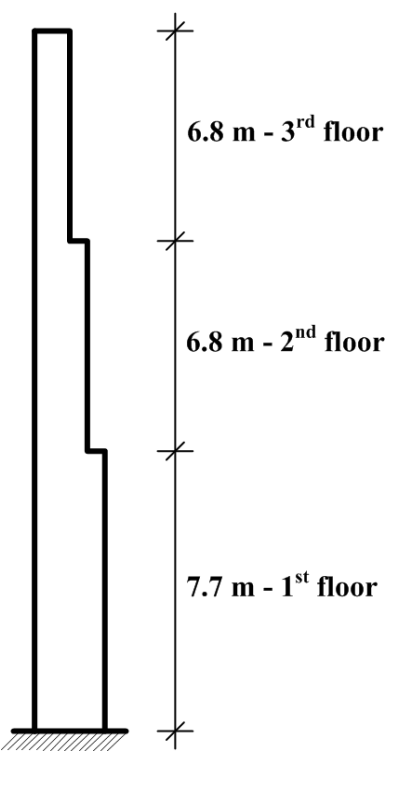

b)

Figure 4: Adopted geometry: a) first floor; b) wall section. 


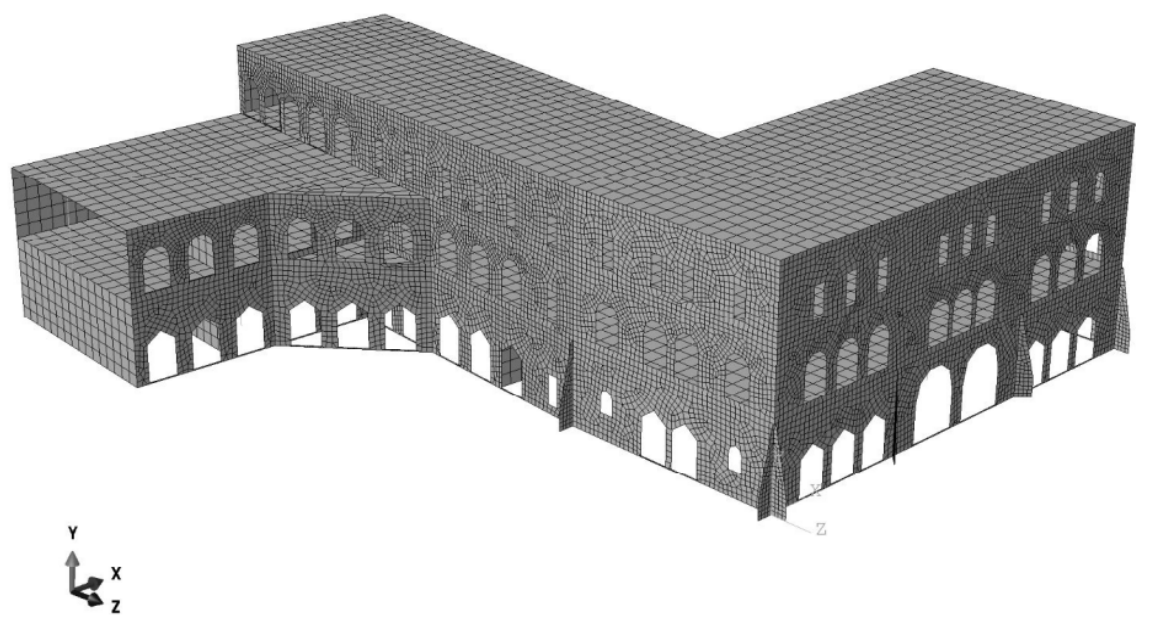

Figure 5: FEM mesh of the building. 


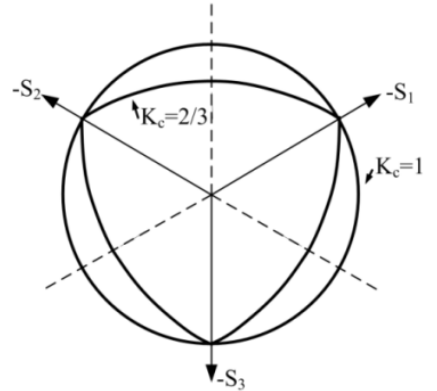

a)

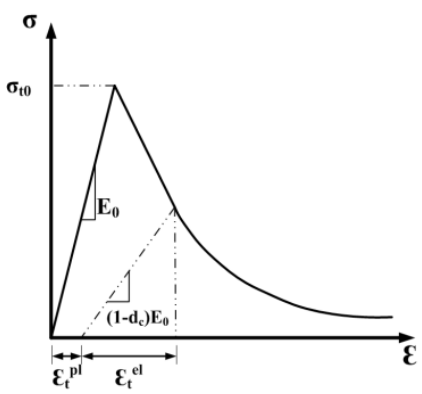

b)

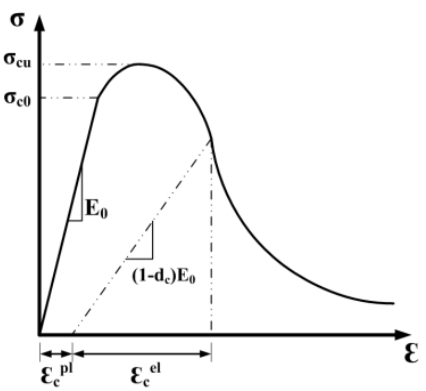

c)

Figure 6: CDP material model: a) failure surface, represented in the deviatoric plane S1, $\mathrm{S} 2$ and $\mathrm{S} 3$; b) stress-strain relation in tension; c) stress-strain relation in compression [20]. 


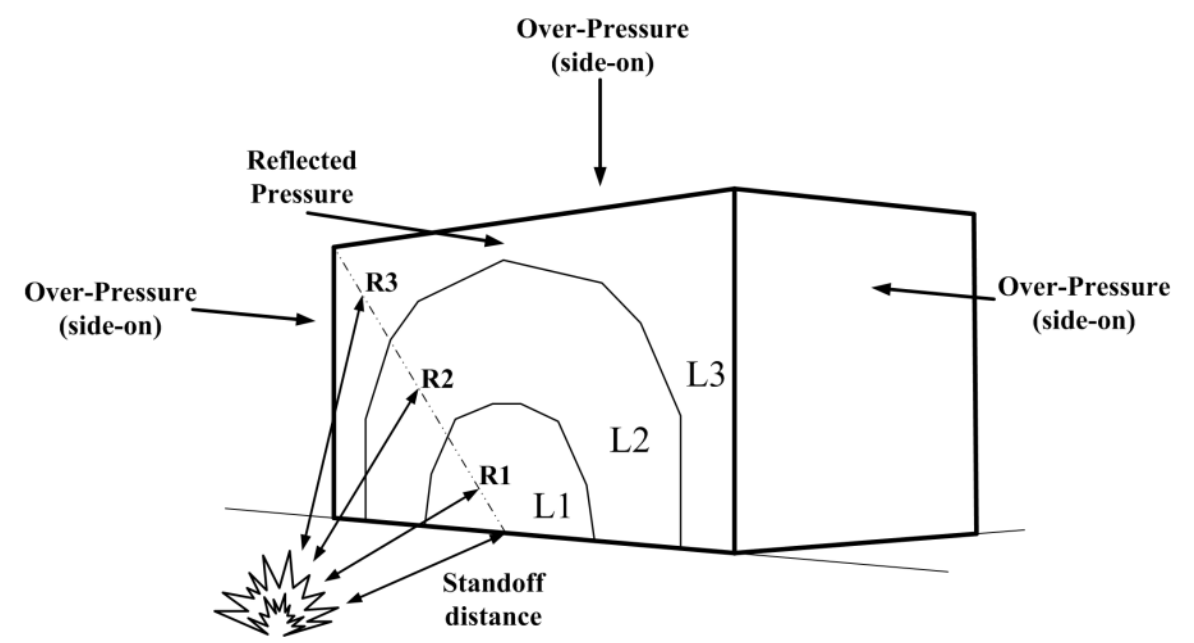

Figure 7: Blast loading distribuition. 


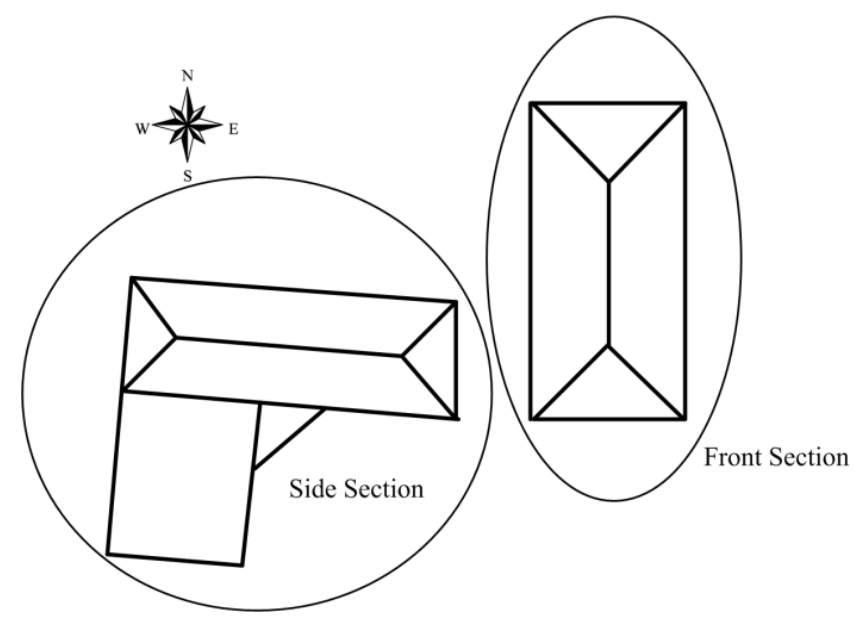

Figure 8: Sections of the building for different scenarios. 


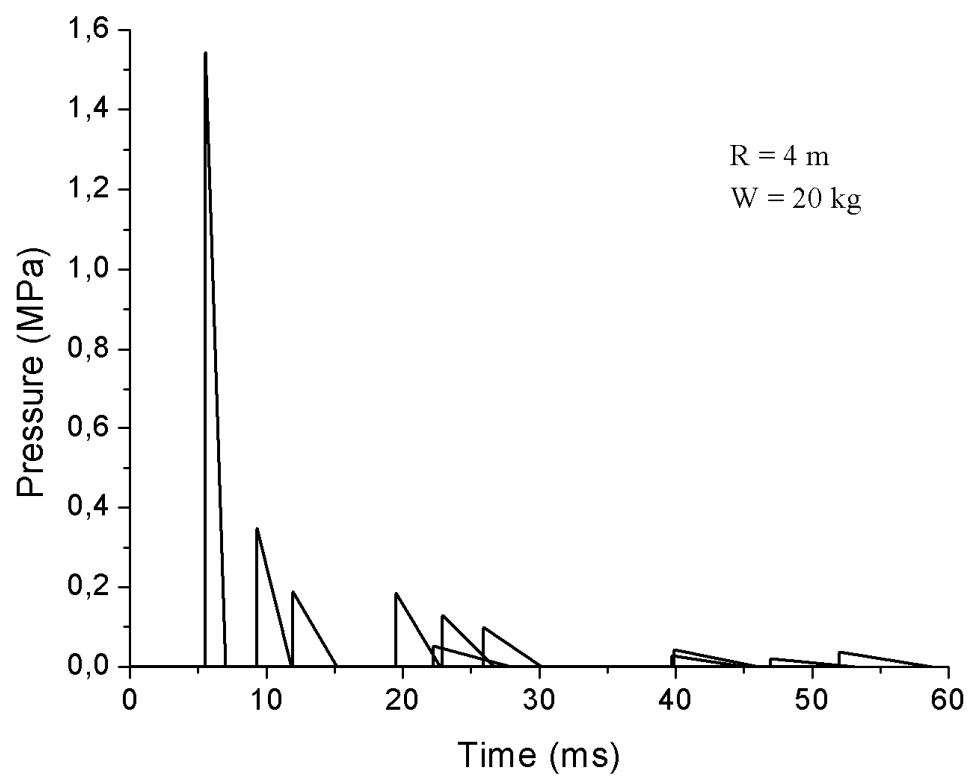

Figure 9: Pressure profiles for scenario A. 


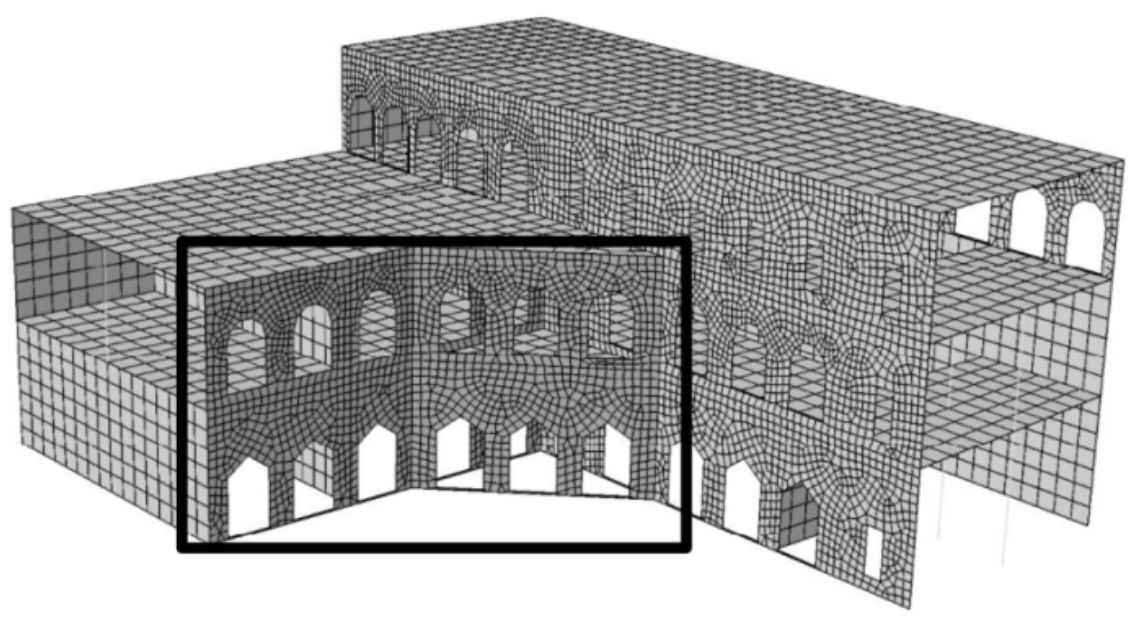

Figure 10: FEM mesh of the side section. 


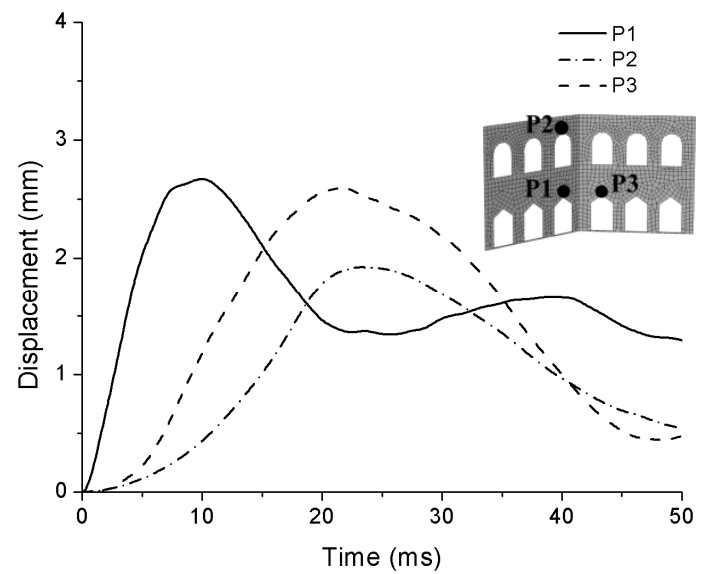

a)

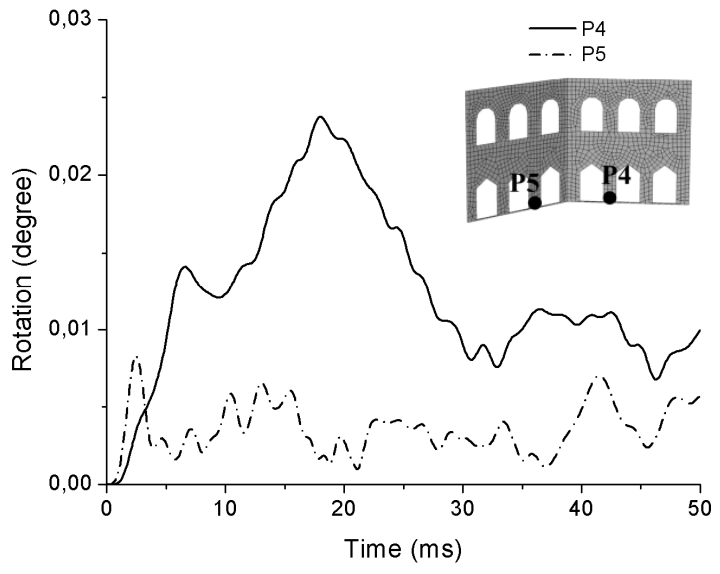

b)

Figure 11: Time histories: a) displacement; b) rotations at supports. 


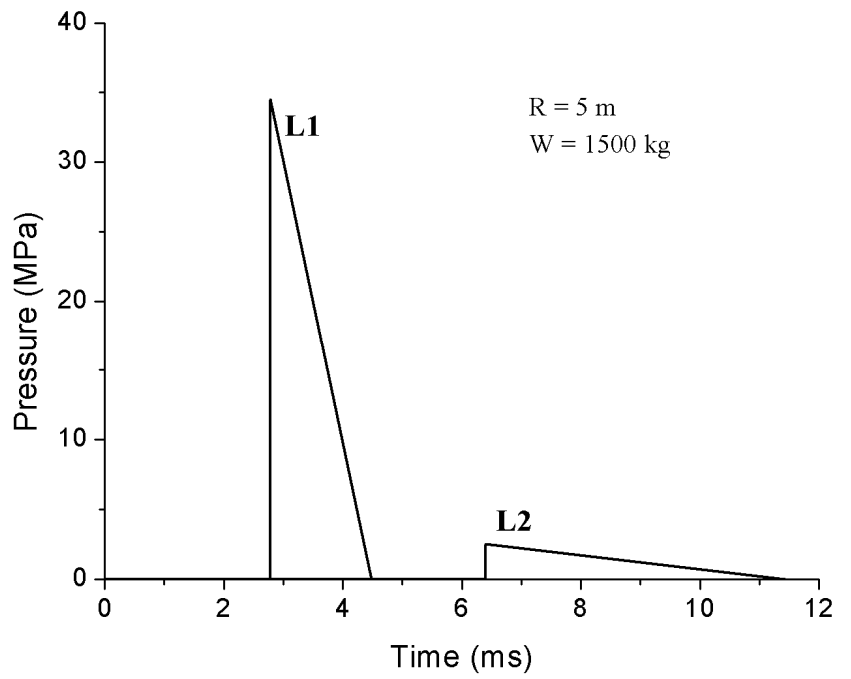

Figure 12: Pressure profiles for scenario B in the L1 and L3 regions of the front section. 


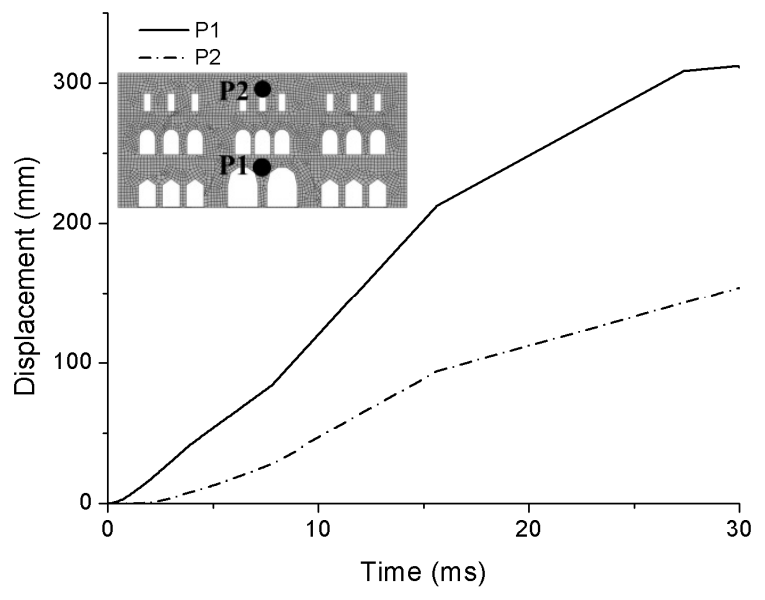

a)

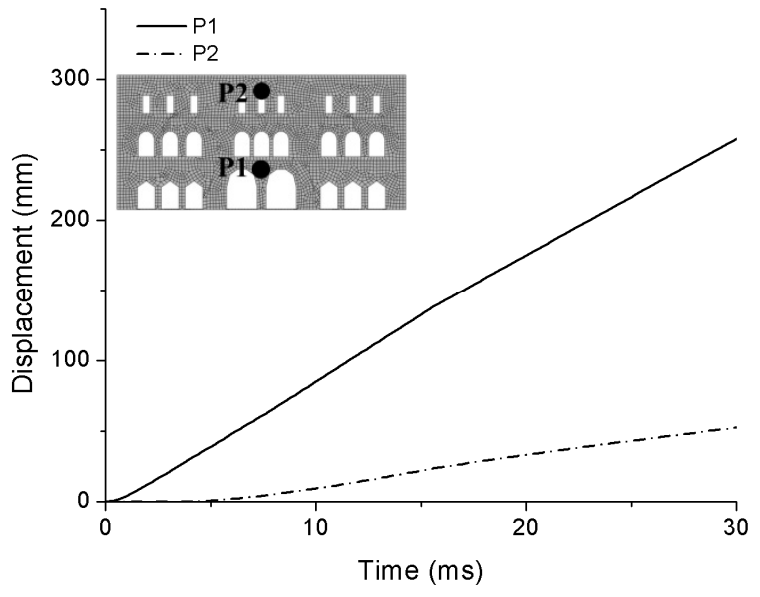

b)

Figure 13: Displacement time history for scenario B: a) neglecting pavements;

b) considering pavements. 


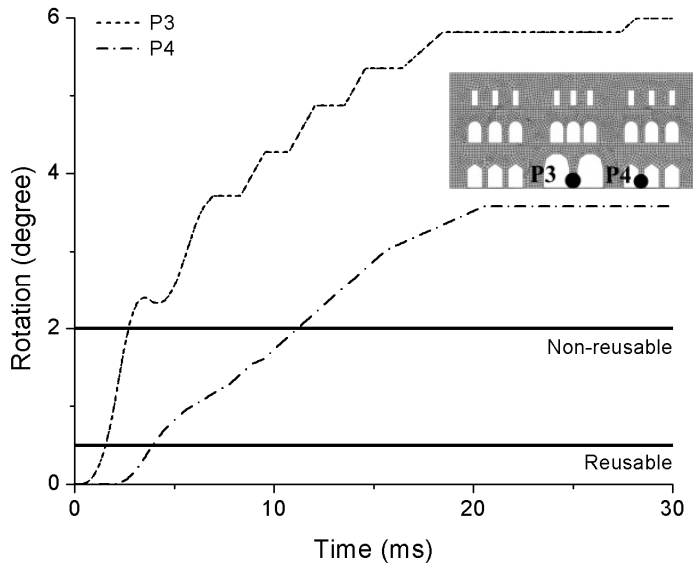

a)

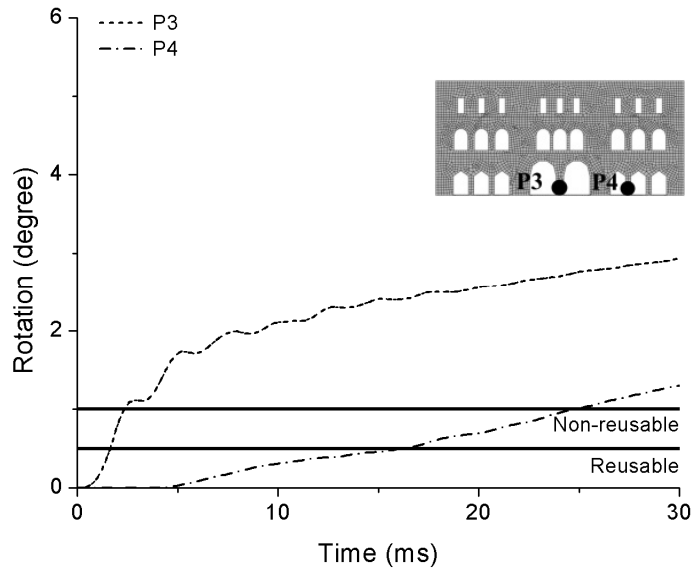

b)

Figure 14: Rotations time history for scenario B: a) neglecting pavements;

b) considering pavements. 


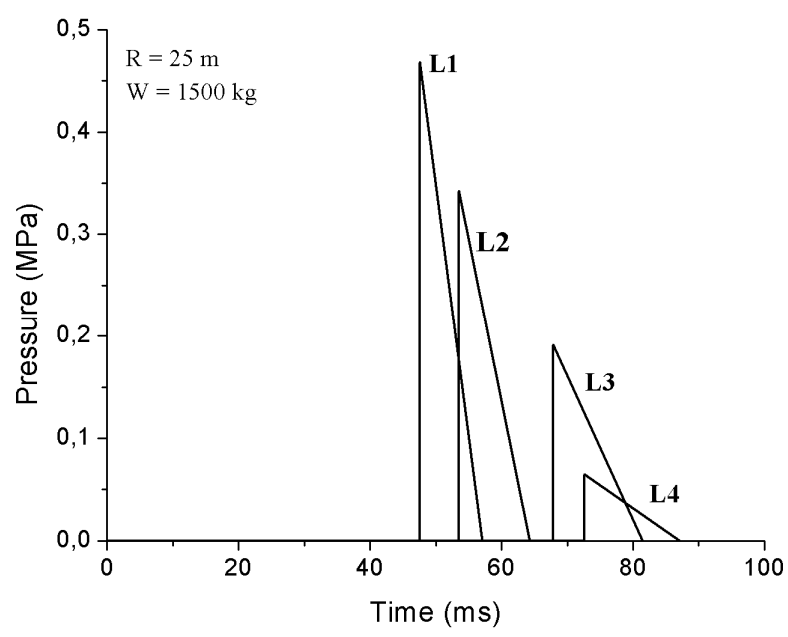

Figure 15: Pressure profiles for scenario B'. 


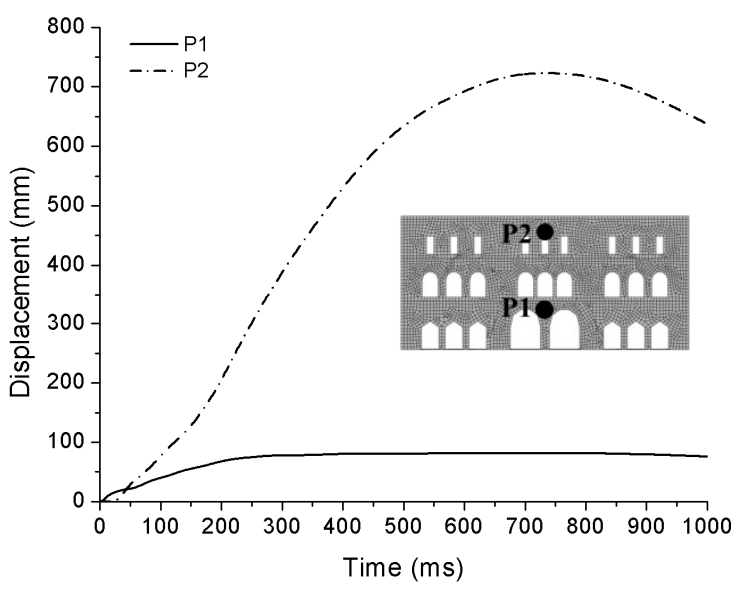

a)

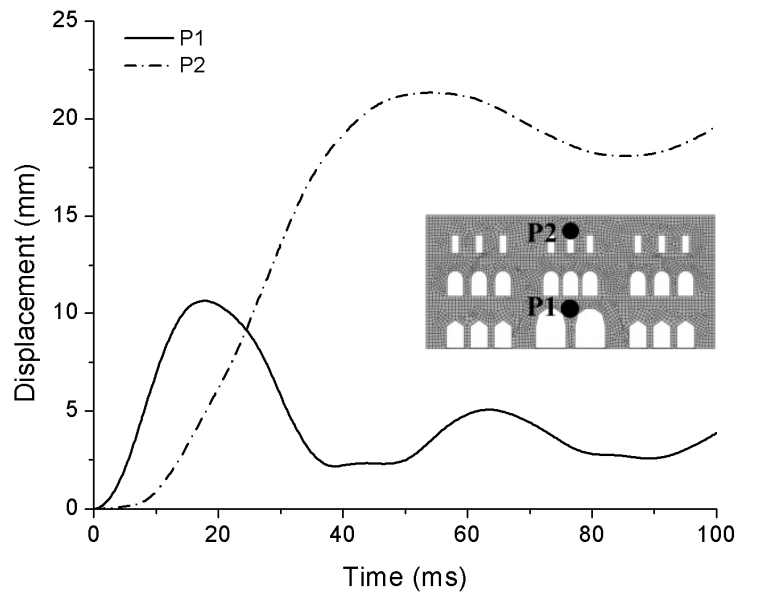

b)

Figure 16: Displacement time history for scenario B': a) neglecting pavements;

b) considering pavements. 


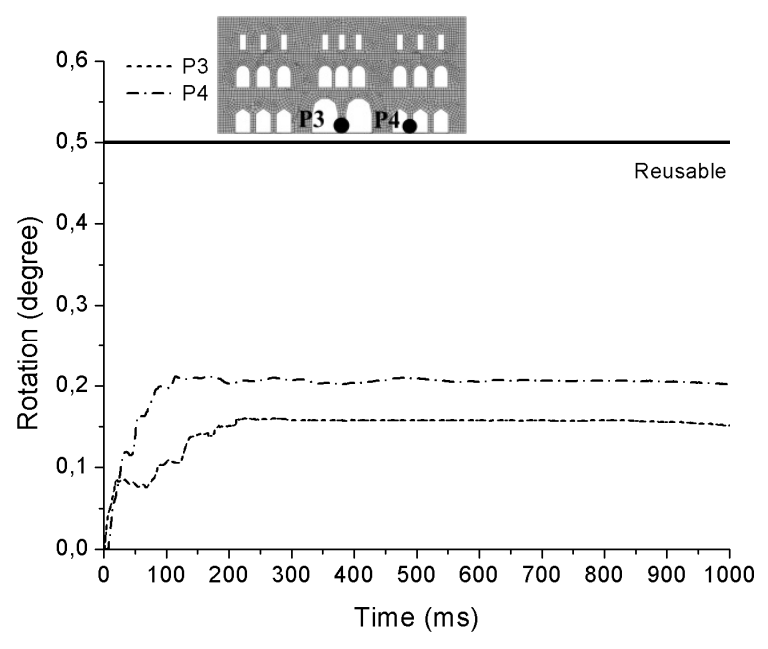

a)

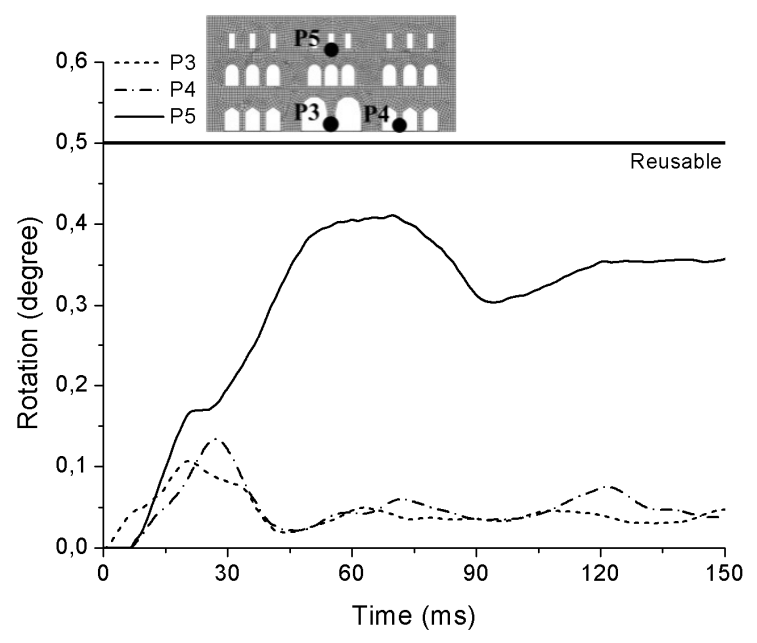

b)

Figure 17: Rotations time history for scenario B': a) neglecting pavements;

b) considering pavements. 


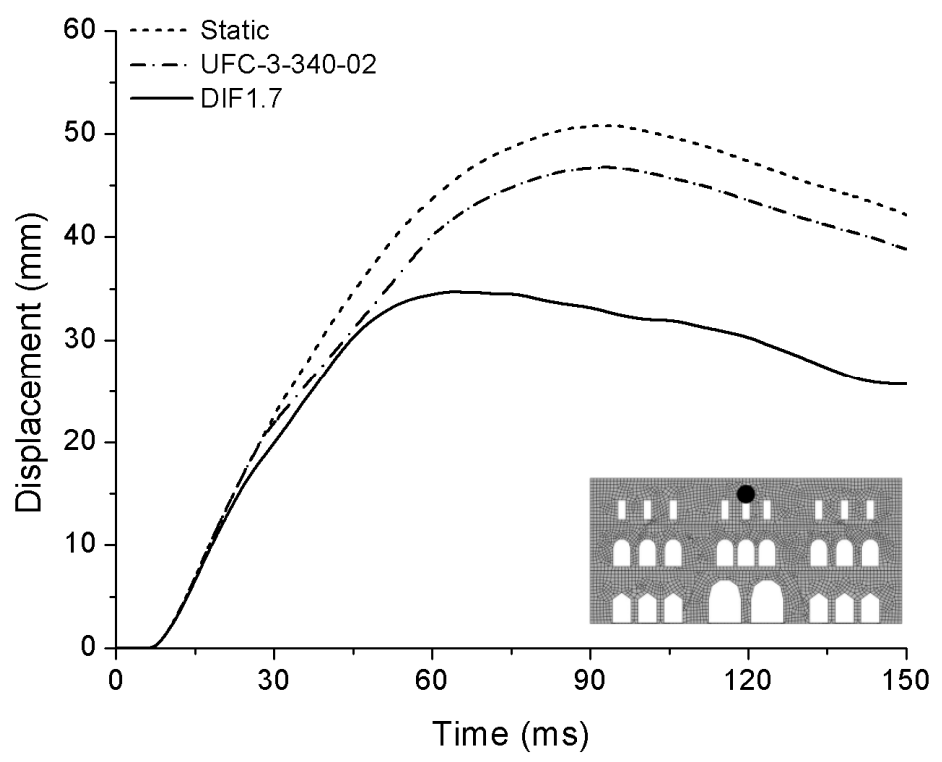

Figure 18: Maximum displacement for different material properties. 